University of Windsor

Scholarship at UWindsor

$11-20-2019$

\title{
Covalently Functionalized Sawdust for the Remediation of Phosphate from Agricultural Wastewater
}

\author{
Daniel Meister \\ Department of Chemistry and Biochemistry, University of Windsor \\ David Ure \\ Department of Chemistry and Biochemistry, University of Windsor \\ Angela Awada \\ Department of Chemistry and Biochemistry, University of Windsor \\ Jean-Claude Barrette \\ Department of Earth and Environmental Sciences, University of Windsor \\ Joel Gagnon \\ Department of Earth and Environmental Sciences, University of Windsor
}

See next page for additional authors

Follow this and additional works at: https://scholar.uwindsor.ca/chemistrybiochemistrypub

Part of the Biochemistry, Biophysics, and Structural Biology Commons, and the Chemistry Commons

\begin{abstract}
Recommended Citation
Meister, Daniel; Ure, David; Awada, Angela; Barrette, Jean-Claude; Gagnon, Joel; Mutus, Bluent; and Trant, John F.. (2019). Covalently Functionalized Sawdust for the Remediation of Phosphate from Agricultural Wastewater. ACS Sustainable Chemistry \& Engineering.

https://scholar.uwindsor.ca/chemistrybiochemistrypub/145
\end{abstract}

This Article is brought to you for free and open access by the Department of Chemistry and Biochemistry at Scholarship at UWindsor. It has been accepted for inclusion in Chemistry and Biochemistry Publications by an authorized administrator of Scholarship at UWindsor. For more information, please contact scholarship@uwindsor.ca. 


\section{Authors}

Daniel Meister, David Ure, Angela Awada, Jean-Claude Barrette, Joel Gagnon, Bluent Mutus, and John F. Trant 


\section{Notice:}

This document is the Accepted Manuscript version of a Published Work that appeared in final form in ACS Sustainable Chemistry \& Engineering, copyright (C) American Chemical Society after peer review and technical editing by the publisher. To access the final edited and published work see https://doi.org/10.1021/acssuschemeng.9b06073. 
Covalently Functionalized Sawdust for the Remediation of Phosphate from Agricultural Wastewater

Daniel Meister, David Ure, Angela Awada, Jean-Claude Barrette, Joel Gagnon, Bulent Mutus*, John F. Trant*

${ }^{1}$ Department of Chemistry and Biochemistry, University of Windsor, 401 Sunset Ave. Windsor, Ontario, N9B 3P4 Canada

${ }^{2}$ Department of Earth and Environmental Sciences, University of Windsor, 401 Sunset Ave. Windsor, Ontario, N9B 3P4 Canada

E: j.trant@uwindsor.ca,

T: 519-253-3000 xt 3528

F: 519-973-7098

E:mutusb@uwindsor.ca

T: 519-253-3000 xt 3526

F: 519-973-7098 


\begin{abstract}
:
Phosphate remediation from wastewater is rapidly becoming an ever more attractive process due to a combination of both the economic pressure of increasing phosphate scarcity and the environmental damage caused by untreated agricultural runoff. Ideally, remediated phosphate will be recoverable and would be able to be reused as fertilizer. Many different resins have been investigated, but due to the scale of the challenge, any feasible solution will involve the use of very inexpensive waste products as the solid support. Sawdust, functionalized with iron-binding ligands, is such a potential resin. Sawdust alone binds $0.3 \mathrm{~g} / \mathrm{kg}$ of phosphate which is insufficient. Iron has a strong affinity for phosphate, making the formation of iron-phosphate bonds a promising avenue for the development of recyclable resins. Previously prepared iron-chitosan complexes bound 8.2 $\mathrm{g} / \mathrm{kg}$. However, as the price of chitosan has rapidly increased, alternatives are required. In this current study, the covalent modification of the sawdust using either carboxymethylcellulosesupported ligands, or direct functionalization of the sawdust can increase this to $40 \mathrm{~g} / \mathrm{kg}$ using ethylene diamine as the iron-binding ligand. Binding decreases over repeated cycles of phosphate exposure and elution, but can be fully restored through regeneration using iron salts. The simple green synthesis of this material, and the iron-binding capability of the investigated ligands is discussed. These sawdust-based resins show promise as potential candidates for industrial-scale phosphate recovery efforts in the future.
\end{abstract}

Keywords: phosphate remediation, wastewater, iron, chelation, cellulose, deferasirox, carboxymethylcellulose, immobilization 


\section{Introduction}

The growing global population will continue to require ever increasing quantities of food. As a result, ever-increasing crop yields are essential to maintain adequate global food supplies. Since the agricultural revolution, fertilizers rich in the macronutrients nitrogen, potassium and phosphorous have been applied to fields to increase yields. ${ }^{1}$ Phosphorous tends to be the limiting nutrient for crop growth. ${ }^{2}$ Historically organic phosphorous was supplied in the form of manures and organic waste. Modern fertilizers employ inorganic phosphate (Pi) sourced from rock phosphate. $^{1}$

Application of $\mathrm{Pi}$ rich fertilizers leads to the leeching and runoff of $\mathrm{Pi}$ into waterways. Accumulation of Pi leads to a form of premature lake aging called eutrophication. ${ }^{3}$ As in the fields, $\mathrm{Pi}$ is the limiting nutrient in algal and aquatic plant growth. ${ }^{4}$ Eutrophication through $\mathrm{Pi}$ accumulation leads to rapid and excessive growth of algae and results in algal bloom formation. ${ }^{5}$ These blooms can be toxic and result in increased mass fish kills. This is not only environmentally damaging, but it also hurts the tourism and fishing industries that many coastal communities rely on. Even non-toxic blooms can damage aquatic systems by leading to rapid fluctuations in $\mathrm{pH}$ and dissolved oxygen. ${ }^{5}$

The easiest way to address this problem is to treat the water near the source to remove the phosphate. Recovery of phosphate is also appealing due to the decrease in the availability of rock phosphate, and the expected increases in price will threaten food security globally. ${ }^{6-8}$ There are a number of different technologies that have been employed, with the formation of sparingly soluble struvite (magnesium ammonium phosphate) being a leading approach. ${ }^{9-10}$ However this method requires the addition of substantial amounts of additional chemicals and further processing. Alternatives include adsorption processes using amorphous adsorbents (from which the phosphate 
is difficult to recover), ${ }^{11-15}$ anionic exchange resins (which face cost challenges), ${ }^{16-17}$ and complex metallic nanotubes, nanoparticles or supramolecular complexes (which also face cost challenges in preparation on scale). ${ }^{18-25}$ Alternative methods, using commonly available agricultural or food production waste products might prove more economically feasible at the industrial scale. ${ }^{26}$

Several biopolymer systems have been employed, including cellulose, ${ }^{27-28}$ sawdust, ${ }^{29}$ and, previously from our lab, chitosan. ${ }^{30}$ Chitosan is produced industrially by the deacetylation of chitin a natural biopolymer sourced from shellfish. It is effective at Pi remediation, but it suffers from two distinct disadvantages; a relatively short lifespan when exposed to waterborne microorganisms and increasing price over the preceding five years. Alternatively, cellulose is the most abundant biopolymer on Earth and easily obtainable at low cost in a wide variety of forms. The use of polysaccharidic materials including chitin and chitosan have long been investigated for their use in the filtration of heavy metals from wastewater. ${ }^{31}$ Both modified and unmodified cellulosic materials have been utilized to remediate Pi from wastewater. ${ }^{12,27}$

Wood pellets and sawdust are excellent, readily available, inexpensive forms of cellulose and are formed as waste products (or created from waste products in the case of wood pellets) in lumber processing. However, cellulose itself does not bind Pi to any appreciable extent. Iron cellulose composites have shown some promise for Pi-removal but the non-covalently bound iron tends to be readily removed upon repeated washing, limiting the recyclability of the material. ${ }^{12}$ To overcome this limitation we envisioned changing the surface functionalization of the sawdust to incorporate iron-binding moieties. Iron has exceptional selectivity and affinity for phosphate ${ }^{11}$ and binding the iron tightly to the particles using iron-specific ligands would allow for recycling through anion exchange. In our preferred iteration, the iron-functionalized sawdust particles would be treated with the wastewater to phosphate saturation, and then washed with an inexpensive and 
non-toxic anionic polymer such as carboxymethyl cellulose, or an inexpensive non-toxic salt, such as sodium acetate, to exchange the ligands and recycle the sawdust with limited loss in phosphatebinding capacity. After several cycles, the resin could be regenerated using a fresh solution of iron salts to recover any lost iron. This will allow for the preparation of reusable resins, an unmet need in the field.

Previous work had identified carboxymethyl cellulose (CMC) as a potential coating to enhance the Pi-remediation capabilities of woodchips by improving iron-binding capacity over native cellulose. ${ }^{32}$ Building on this result, we sought to covalently immobilize CMC, pre-functionalized with iron-binding ligands, on sawdust.

Our initial ligand of choice for this surface modification was deferasirox. It has been used as a drug to chelate iron in the blood of patients with chronic iron overload and has extremely high and selective binding affinity to iron. ${ }^{33-34}$ In solution it forms a dimer around a single iron (III) atom, but on the solid phase this would not be possible, so it would provide three open co-ordination sites for a phosphate atom. Deferasirox's binding affinity for iron is exceptional at $\log \beta=36.9$ at $\mathrm{pH}>6.0,{ }^{35}$ and is, to the best of our knowledge, the best Fe (III) binder known. Deferasirox has the added benefit of having a straightforward and inexpensive synthesis. ${ }^{35}$ However, we were concerned that the affinity might be too high, making the Fe (III) too electron rich. This would lower the affinity for phosphate, so several other ligands were also of interest including amino acids, and ethylenediamine. These ligands have nitrogen and oxygen atoms potentially capable of chelating iron and could potentially act co-operatively with the hydroxyl functionalities naturally present on the sawdust surface. These simple reserve ligands were chosen to both minimize cost of manufacture, while maintaining sufficient iron-binding capability to be functional. The results of this study, and the nature of the high affinity, highly recyclable resins prepared, are reported 
here.

\section{Experimental}

General Experimental Procedure: Solvents were purchased from Caledon Labs (Caledon, Ontario), Sigma-Aldrich (Oakville, Ontario) or VWR Canada (Mississauga, Ontario). Sawdust (McFeeters, 78L, softwood: pine, average diameter $1 \mathrm{~cm}$ ) was obtained from TSC Stores (London,

Canada). Other chemicals were purchased from Sigma-Aldrich, AK Scientific, Oakwood Chemicals, Alfa Aesar or Acros Chemicals and were used without further purification unless otherwise noted. All heated reactions were conducted using oil baths on IKA RET Basic stir plates equipped with P1000 temperature probes. Thin layer chromatography was performed using EMD aluminum-backed silica 60 F254-coated plates and were visualized using either UV-light (254 nm), $\mathrm{KMnO}_{4}$, vanillin, Hanessian's stain, or Dragendorff's stain. Standard work-up procedure for all reactions undergoing an aqueous wash involved back extraction of every aqueous phase, a drying of the combined organic phases with anhydrous magnesium sulphate, filtration either using vacuum and a sintered-glass frit or through a glass-wool plug using gravity, and concentration under reduced pressure on a rotary evaporator (Buchi or Synthware). ${ }^{1} \mathrm{H}$ NMR spectra were obtained at $300 \mathrm{MHz}$ or $500 \mathrm{MHz}$ on Bruker instruments with analysis being carried out using TopSpin, NMR chemical shifts $(\delta)$ are reported in ppm and are calibrated against residual solvent signals of $\mathrm{CHCl}_{3}(\delta 7.26)$, DMSO-d $\mathrm{d}_{5}(\delta 2.50)$, acetone- $\mathrm{d}_{5}(\delta 2.05)$, or methanol- $\mathrm{d}_{3}(\delta 3.31)$.

\section{Synthesis of the Conjugatable Deferasirox}

2-(2-hydroxyphenyl)-4H-benzo[e][1,3]oxazin-4-one (1): Salicylic acid (20 g, $0.145 \mathrm{~mol})$, salicylamide $(16.54 \mathrm{~g}, 0.121 \mathrm{~mol})$ and pyridine $(1.28 \mathrm{~mL}, 0.016 \mathrm{~mol})$ were dissolved in $50 \mathrm{~mL}$ of xylene, and the mixture was heated to reflux for 15 minutes. $\mathrm{SOCl}_{2}(19.22 \mathrm{~mL}, 0.265 \mathrm{~mol})$ was 
then added slowly over 4 hours while at reflux with vigorous stirring, followed by another 20 hours of stirring. Xylene was removed by concentrating under reduced pressure resulting in an acidic residue. This was resuspended in ethanol $(50 \mathrm{~mL})$ and acetic acid $(1.2 \mathrm{~mL})$. This mixture was heated to reflux and then cooled to room temperature. Following filtration and washing with cold ethanol, the resulting precipitate was dried to yield 2-(2-hydroxyphenyl)-4H-benzo[e][1,3]oxazin4-one (24.85g, 86\% yield). ${ }^{1} \mathrm{H}-\mathrm{NMR}\left(300 \mathrm{MHz},\left[\mathrm{D}_{6}\right.\right.$ ] DMSO) 7.09 (d, J=7.99 Hz, $2 \mathrm{H}$ ), 7.58-7.67 (m, 2H), 7.78-7.81 (m, 1H), 7.92-7.98 (m, 1H), 8.07 (dd, J=1.59 Hz, 1H), 8.21 (dd, J=1.68 Hz, 1H). Spectroscopic data is consistent with the literature. ${ }^{35}$

4-(3,5-bis(2-hydroxyphenyl)-1,2,4-triazolidin-1-yl)benzoic acid (Deferasirox): 4-hydrazino benzoic acid $(9.54 \mathrm{~g}, 63 \mathrm{mmol})$ and $\mathrm{Et}_{3} \mathrm{~N}(8.74 \mathrm{~mL}, 63 \mathrm{mmol})$ were added to $\mathrm{EtOH}(271 \mathrm{~mL})$. The solution was heated to reflux for 15 minutes until fully homogenous. To this hot clear solution was added $\mathbf{1}$, and the reaction was heated to reflux for an additional 2 hours. After cooling to room temperature, water was added $(30 \mathrm{~mL})$ until precipitation was observed. The mixture was then concentrated to $50 \%$ total volume (to about $150 \mathrm{~mL}$ ) under reduced pressure and $6 \mathrm{M} \mathrm{HCl} \mathrm{(300}$ $\mathrm{mL}$ ) was added. The resulting precipitate was isolated and dried to yield crude deferasirox. This was further purified by suspending in boiling isopropanol $(10 \mathrm{~mL}$ per $1 \mathrm{~g}$ of crude) and alternatively sonicating and boiling the material to maximize dissolution. A hot filtration removed (undissolved) unreacted 4-hydrazinobenzoic acid to provide a solution of pure deferasirox which was concentrated under reduced pressure. (17.66 g, 75.5\% yield). ${ }^{1} \mathrm{H}-\mathrm{NMR}$ (300 MHz, [D $]$ DMSO) $6.85(\mathrm{~d}, \mathrm{~J}=8.16 \mathrm{~Hz}, 1 \mathrm{H}), 6.96-7.03(\mathrm{~m}, 3 \mathrm{H}), 7.35-7.42(\mathrm{~m}, 2 \mathrm{H}), 7.55$ (d, J=7.44 Hz, 3H), $7.98(\mathrm{~d}, \mathrm{~J}=8.47 \mathrm{~Hz}, 2 \mathrm{H}), 8.04$ (d, J=7.57 Hz, 1H), 10.05 (s, OH), 10.80 (s, OH), 13.21 ( broad s. $\mathrm{OH})$. Spectroscopic data is consistent with the literature. ${ }^{35}$ 
N-(2-aminoethyl)-4-(3,5-bis(2-hydroxyphenyl)-1,2,4-triazolidin-1-yl)benzamide: Deferasirox

$(0.50 \mathrm{~g}, 1.34 \mathrm{mmol})$ was added to $10 \mathrm{~mL}$ of dioxane under nitrogen, then cooled to $0^{\circ} \mathrm{C}$. DIPEA was then added (1.34 mmol) followed by N,N'-Dicyclohexylcarbodiimide (DCC) (1.47 mmol) and the reaction mixture stirred for 5 minutes. Ethylenediamine $(8.04 \mathrm{mmol})$ was then quickly added in one portion, and the mixture was warmed to room temperature followed by stirring for an additional 2 hours. The product precipitated from the reaction mixture and stuck to the flask as a brown solid. The reaction mixture was filtered, and the precipitate was washed with dioxane then ether to obtain the product (42\% yield). ${ }^{1} \mathrm{H}-\mathrm{NMR}\left(300 \mathrm{MHz}, \mathrm{D}_{2} \mathrm{O}\right) \delta_{\mathrm{ppm}}: 3.16(\mathrm{t}, 2 \mathrm{H}, J=5.73 \mathrm{~Hz})$, $3.66(\mathrm{t}, 2 \mathrm{H}, J=5.76 \mathrm{~Hz}), 6.62-6.73(\mathrm{~m}, 2 \mathrm{H}), 6.76-6.81(\mathrm{~m}, 2 \mathrm{H}), 6.91(\mathrm{t}, 2 \mathrm{H}, J=8.3 \mathrm{~Hz}), 7.28-7.35$ $(\mathrm{m}, 2 \mathrm{H}), 7.75-7.82(\mathrm{~m}, 4 \mathrm{H})$. Spectral data is consistent with the literature. ${ }^{36}$

\section{Preparation of the Sawdust and conjugation to the organic ligands}

Synthesis of CMC-chelation derivatives: Standard 1-ethyl-3-(3'-(dimethylamino)propyl) carbodiimide (EDC) coupling procedures were used in the coupling of amino acids to CMC. CMC (1 equiv.) was suspended in DMF and cooled to $0{ }^{\circ} \mathrm{C}$ in an ice bath. To this $\mathrm{EDC}$ (1.1 equiv.) was added followed by 5 minutes of stirring at $0{ }^{\circ} \mathrm{C}$. A mixture of the amine (1.1 equiv.) with DIPEA (2.5 equiv.) in DMF was then added. The mixture was warmed to room temperature and stirred for $18 \mathrm{~h}$, followed by filtration to collect CMC which was washed with DMF and dried.

Sawdust Epoxidation: Sawdust was thoroughly washed with water and dried overnight at $50{ }^{\circ} \mathrm{C}$. In a beaker, $1 \mathrm{~g}$ of sawdust was suspended in $12 \mathrm{~mL}$ of dioxane. To this $10 \mathrm{~mL}$ of epichlorohydrin was added, followed by $6 \mathrm{~mL}$ of $5 \mathrm{M} \mathrm{NaOH}$. The mixture was stirred gently for 5 hours at $60{ }^{\circ} \mathrm{C}$ then left stirring overnight at room temperature. The product was washed with dioxane and $0.1 \mathrm{M}$ $\mathrm{NaHCO}_{3}$, then dried under reduced pressure. 
General Sawdust functionalization procedure with CMC: A mixture of the functionalized CMC $(0.6 \mathrm{~g})$, DIPEA $(2 \mathrm{~mL})$, and epoxide functionalized sawdust in DMF $(100 \mathrm{~mL})$ was heated for $6 \mathrm{hrs}$ at $60{ }^{\circ} \mathrm{C}$ followed by stirring for 18 hours at room temperature. Afterwards the functionalized sawdust was collected by filtration, rinsed extensively with water and dried.

General Direct Sawdust functionalization procedure: Epichlorohydrin functionalized sawdust was suspended in dimethylformamide (DMF). To this, a mixture of the chelator $(6 \mathrm{mmol}$ chelator/g sawdust) with DIPEA (0.5-1 equiv.) was added and the mixture stirred gently for 24 hours. Dioxane was initially used as a solvent however due to the poor solubility of the deferasirox substituent, was replaced with DMF. The EDA chelator was also tested in dioxane as well as in water with $0.75 \mathrm{M} \mathrm{NaOH}$ as the base. Use of water $/ \mathrm{NaOH}$ offers a greener and cheaper alternative for functionalization. Note: the chelator is used in large excess and did not completely react with the sawdust. For example, an analysis of the amount of excess deferasirox-EDA ligand recovered following coupling showed that only about $0.11 \mathrm{mmol}$ per gram sawdust reacted and the rest was recovered. This equates to $2 \%$ of the chelator added reacting with the sawdust. In contrast, EDA in water $/ \mathrm{NaOH}$ couples with $60 \%$ efficiency as measured by ${ }^{1} \mathrm{H}$ NMR by comparing the reaction mixture before coupling $\left(\mathrm{D}_{2} \mathrm{O}\right.$ as solvent) with the reaction mixture after coupling using the residual water peak as an internal quantitative standard (see SI for details, Figure S14 and S15) indicating a much higher ligand loading of $3.6 \mathrm{mmol} / \mathrm{g}$ of sawdust.

\section{Iron Functionalization of Synthetically Modified Cellulose Biopolymers}

Modified cellulose polymers with bound ligands ( $\sim 5 \mathrm{~g}$ ) were subjected to $50 \mathrm{mM}$ iron (III) sulfate baths $(250 \mathrm{~mL})$ overnight at a constant $100 \mathrm{rpm}$ spin on a magnetic stir plate. Filtration, extensive washing with water, and drying in vacuo provided the iron-functionalized resins. 


\section{Phosphate Binding Assays}

After iron functionalization, samples were thoroughly rinsed with $1 \mathrm{M} \mathrm{NaCl}$ to remove any bound Pi. Approximately five grams of sample material was placed in $100 \mathrm{~mL}$ BioRad columns with glass wool as filters. The columns were rinsed with $600 \mathrm{~mL}$ of Milli-Q water and soaked in 100 $\mathrm{mL}$ of $1 \mathrm{M}$ phosphate buffer, $\mathrm{pH} 7.4$ for 30 minutes. The columns were then rinsed with $600 \mathrm{~mL}$ of Milli-Q water to remove any unbound Pi. Elution of the bound phosphate was conducted using a $0.1 \%(w / v) ~ C M C ~ s o l u t i o n, ~ p H=7.4 .{ }^{37}$ Samples were soaked in $80 \mathrm{~mL}$ of the CMC solution for 30 minutes. During elution, a further $100 \mathrm{~mL}$ of the $\mathrm{CMC}$ solutions was passed through the column and combined with the initial elution solution. The combined elution samples were collected in $200 \mathrm{~mL}$ volumetric flasks. The $180 \mathrm{~mL}$ volume of the eluant was increased to a constant $200 \mathrm{~mL}$ for all samples. One millilitre of this solution was collected for later Pi concentration determination. Each sample was exposed to three sequential binding-elution cycles. Samples demonstrating high Pi binding capacity were tested for Pi retention in the presence of interfering anions. A $1 \mathrm{M} \mathrm{Pi}$, $\mathrm{pH}=7.4$ solution, was made containing $10 \mathrm{mM} \mathrm{Na}_{2} \mathrm{SO}_{4}, 10 \mathrm{mM} \mathrm{NaNO}_{3}$ or $10 \mathrm{mM}$ of both $\mathrm{Na}_{2} \mathrm{SO}_{4}$ and $\mathrm{NaNO}_{3}$.

Determination of total bound Pi was accomplished by measuring the Pi concentration of eluted samples in comparison to the dry weight of the binding matrix using the modified malachite green assay (MG-assay) mentioned below. There was no significant difference in binding capacity from one cycle to the next. Note, all solutions were prepared in Milli-Q ultrapure water. All reported concentrations are provided with the standard error of the mean.

\section{Modified Malachite Green Assay for Phosphate:}


To $700 \mu \mathrm{L}$ of aqueous analyte, $130 \mu \mathrm{L}$ of reagent $\mathrm{A}$ ( $1 \mathrm{mM}$ malachite green carbinol hydrochloride, $1 \%$ polyvinyl alcohol, $\left.0.6 \mathrm{M} \mathrm{H}_{2} \mathrm{SO}_{4}\right)$ and $70 \mu \mathrm{L}$ of reagent $\mathrm{B}(50 \mathrm{mM}$ ammonium molybdate tetrahydrate, $3 \mathrm{M} \mathrm{H}_{2} \mathrm{SO}_{4}$ ) were added. The absorbance at $630 \mathrm{~nm}$ was recorded and compared with a standard curve. The curve was linear between 2 and $10 \mu \mathrm{M}$ of phosphate.

\section{Determination of Apparent Dissociation Constants by analysis using the Hill-Langmuir}

\section{Equation}

Determination of the apparent dissociation constants $\left(\mathrm{K}_{\mathrm{D}} \mathrm{App}\right)$ for EDA- $\mathrm{H}_{2} \mathrm{O}$ and EDA-dioxane were conducted by suspending $\sim 0.4 \mathrm{~g}$ of binding resin in $4 \mathrm{~mL}$ of water. Initial conditions were determined by removing $100 \mu \mathrm{L}$ of the supernatant, that was then immediately replaced with 100 $\mu \mathrm{L} 2 \mathrm{M} \mathrm{Pi}, \mathrm{pH}=7.4$. The solution was incubated for 300 seconds, and $100 \mu \mathrm{L}$ of the sample was withdrawn and replaced with $100 \mu \mathrm{L}$ of fresh $2 \mathrm{M}$ Pi solution. Each of the collected samples was used to determine free Pi concentration after each addition.

Free Pi concentration was measured by the ascorbic acid - molybdate assay for phosphate shown below. In combination with known total phosphate concentrations, the bound phosphate was determined. From this data, the maximum bound phosphate was determined for each sample. Data were converted into fractional saturations and fit to the Hill-Langmuir Equation (Eq. 1) where $\theta$ is the fractional saturation of available binding sites, $\mathrm{L}$ is the free Pi concentration and $\mathrm{n}$ is the Hill coefficient. ${ }^{38-40}$

(1) $\theta=\frac{[L]^{n}}{K_{D A p p}+[L]^{n}}$ 
Working reagent, made from 2 parts water and 1 part each of reagents A $(2 \%(\mathrm{w} / \mathrm{v})$ ammonium molybdate tetrahydrate), B $\left(10 \%(\mathrm{w} / \mathrm{v})\right.$ ascorbic acid) and $\mathrm{C}\left(3 \mathrm{M} \mathrm{H}_{2} \mathrm{SO}_{4}\right)$, was prepared immediately prior to sample testing. Then, to $100 \mu \mathrm{L}$ of the aqueous analyte, $100 \mu \mathrm{L}$ of the working reagent was added. Samples were incubated at $37{ }^{\circ} \mathrm{C}$ for 60 minutes to allow reaction and colour development. The absorbance at $820 \mathrm{~nm}$ was recorded and compared with a standard curve. The curve was linear from 10 to $150 \mu \mathrm{M}$ of phosphate. Note, all solutions were prepared in Milli-Q ultra pure water.

\section{Measurement of Bound Iron Content in the Sawdust Matrix}

\section{Sample Preparation for Inductively Coupled Plasma Optical Emission Spectroscopy}

Portions of the solid matrix were obtained from each resin sample and each was independently treated with phosphate, regenerated with $0.1 \%(\mathrm{w} / \mathrm{v})$ carboxymethyl cellulose solution, and retreated with phosphate for a total of 6 regeneration cycles. Approximately $20 \mathrm{mg}$ portions from each cycle, including the initial matrix before treatment with phosphate, were collected. This sawdust sample was suspended in $3 \mathrm{~mL}$ of conc. $\mathrm{H}_{2} \mathrm{SO}_{4}$, heated to $70{ }^{\circ} \mathrm{C}$ and shaken for 4 days. The resulting slurry was then diluted using $7 \mathrm{~mL}$ of $\mathrm{dH}_{2} \mathrm{O}$ and filtered through $0.2 \mu \mathrm{m}$ syringe filters. These were then further diluted approximately 40 -fold in distilled water and analyzed. Inductively Coupled Plasma Optical Emission Spectrophotometry (ICP-OES) was conducted using an Agilent Technologies Model \#G8460AA, 720 Series, instrument. Liquid samples are introduced into the axial plasma of the instrument via an Agilent OneNeb series 2 inert concentric type nebulizer combined with a cyclonic spray chamber. Instrument was calibrated against standard mixtures containing either a high or low concentration of standard metals and against the National Research Council of Canada externally certified sample. Iron is measured in triplicate at $259.94 \mathrm{~nm}$, and phosphorous in triplicate at $185.88 \mathrm{~nm}$. Results are the average of the 
three trials. In the cased of the EDA sample, four separate batches of resin (from two different synthetic batches) were subjected to the same process, except 7 wash/elution cycles were conducted. Following the seventh elution, the sawdust was resuspended in the iron (III) sulfate bath and the seven wash/elution cycles were repeated to show the reproducibility of the synthesis and the recyclability of iron binding and phosphate binding behaviour.

\section{Flame Atomic Absorption Spectroscopy}

Samples were run on a Varian 55B atomic absorption spectrometer. Acetylene gas was used as the fuel with air support along with a slit width of $0.2 \mathrm{~nm}$. The lamp was set to a wavelength of $248.3 \mathrm{~nm}$. Three samples, $1.5 \mathrm{ml}$ obtained from each Pi elution cycle of tested sawdust (which has a total volume of $200 \mathrm{~mL}$ ) and results are the average obtained from the three trials.

\section{Results}

\section{Synthesis of phosphate-binding sawdust}

CMC functionalization and immobilization were accomplished using EDC coupling followed by mixing with epoxide-functionalized sawdust in the presence of base (Scheme 1). EDC couplings between an amine and a carboxylic acid are relatively water insensitive and can be carried out effectively in water as solvent. ${ }^{41}$ However, the insolubility of the product made characterization challenging, especially as the CMC products formed thick hydrogels at high concentrations. Lyophilization decreased the water content significantly, but the material is still highly hygroscopic. As the removal of the water and further purification proved difficult, DMF was used as the solvent of choice to avoid these hydrogels. The second step involved reaction of the functionalized $\mathrm{CMC}$ with the epoxide functionalized sawdust, again DMF was used to prevent hydrogel formation and for ease of purification although CMC has limited solubility in DMF. 
Nevertheless, we obtained four CMC-sawdust constructs with 4-amino butyric acid (BA), (S)-2,4diamino butyric acid (DBA), and glycine (Gly). The resulting complexes were characterized by phosphate affinity. The low efficacy and technical complications led us to abandon this approach and turn to direct functionalization of the sawdust.

Regardless of the cellulose source, all materials were treated identically. The wood was suspended in a mixture of dioxane and aqueous sodium hydroxide, to which was added epichlorohydrin, and the mixture stirred at $60^{\circ} \mathrm{C}$ with either mechanical or magnetic stirring. Following washing of the wood to remove excess reagents, the wood was resuspended in solvent (generally dioxane), to which were added diisopropylethylamine and the amine-functionalized ligand. Stirring for an additional 12 hours provided the ligand-functionalized cellulose. Based on literature and chemical precedent, the bulk of the substitution should occur on the C-6 hydroxyl, but functionalization at C-2 and C-3 is, of course, possible (Scheme 2).

The selected ligands, ethylenediamine, (EDA), BA, DBA, and Gly, were commercially available. Deferasirox (DF) was made according to published protocols on $>20 \mathrm{~g}$ scale and is readily available from very inexpensive starting materials (Scheme 3 ) ${ }^{35}$ The benzoic acid moiety plays no role in the iron conjugation, and we used this functionality as a handle to add an amine functionality to allow for cellulose conjugation. 


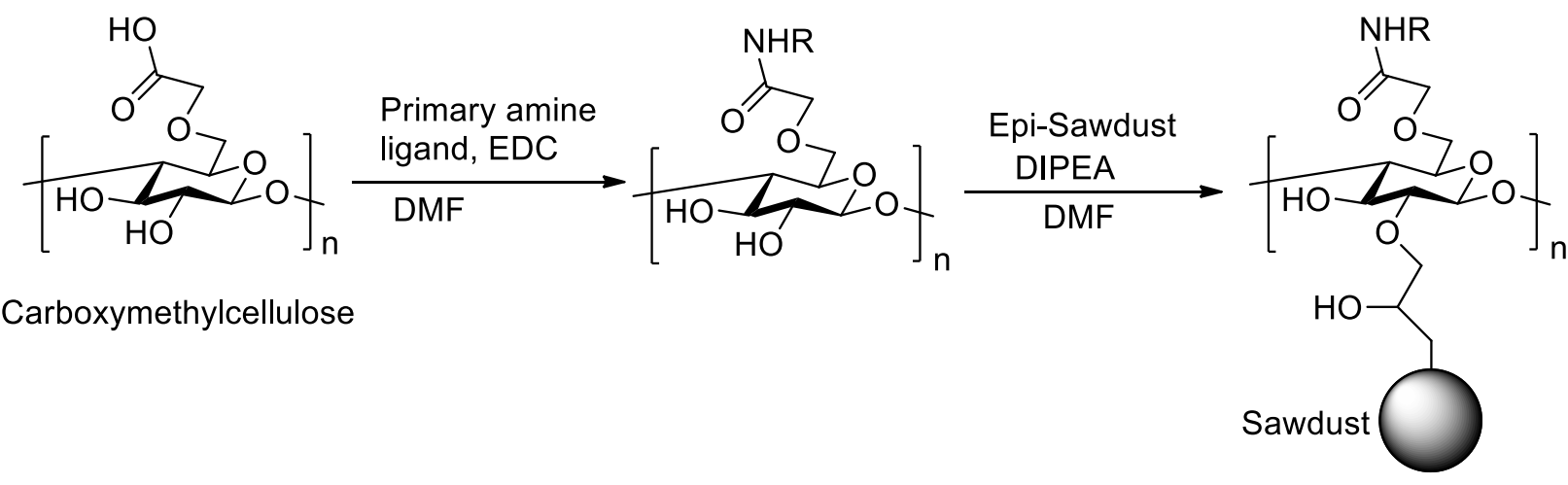

Scheme 1. General route for the preparation of ligand-functionalized sawdust using $\mathrm{CMC} .{ }^{35} \mathrm{CMC}$ has various carboxymethyl groups on the free hydroxyls, and this representation is for illustration purposes only and does not imply that functionalization is occurring on the same monomeric unit or at the indicated positions.

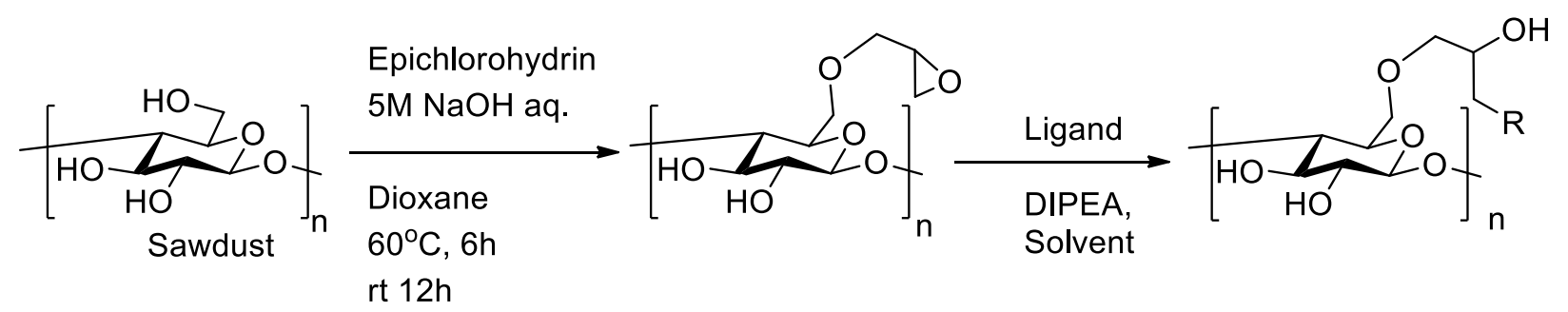

Scheme 2. General route for the preparation of ligand-functionalized sawdust using CMC.

Conjugation between the epichlorohydrin-activated cellulose and the ligands was accomplished in either dioxane or $0.75 \mathrm{M} \mathrm{NaOH}$. The epichlorohydrin-derived oxirane is reactive towards nucleophiles, and we were concerned about competitive reactions between the solvent and the ligand. Consequently, as it was installed in the presence of strong base, and although amines can outcompete hydroxide nucleophiles, we tested both water and dioxane as solvents in the case of 
EDA. The phosphate-binding capacity of both products was similar indicating that solvolysis of the epoxides was not competitive with the amine nucleophiles. However, the reactions are not necessarily highly efficient. In the case of the deferasirox, the lone example where the ligand was easily recoverable following coupling and could be used to determine functionalization efficiency, only $0.11 \mathrm{mmol}$ of ligand $/ \mathrm{g}$ of sawdust was added, representing a $2 \%$ yield based on the amount of ligand added to the reaction. This suggested that either epoxide-loading is inefficient or that ring-opening of the epoxides occurs during epichlorohydrin addition. However, deferasirox was also found to be the most challenging material to work with due to solubility challenges, and we suspected that loading was higher for the other ligands. As the solid-supported products are not soluble, and as the cellulose signals dominate the characterization techniques (i.e. FT-IR), there are few analytical techniques that could be used to determine the success of functionalization. We have obtained the FT-IR spectra of all samples for other researchers to allow for reproducibility (Supporting Information), and the clear differences in phosphate-binding between different formulations, and the batch-to-batch reproducibility of the results gives us confidence in the reproducibility of the methodology. However, we needed another way to quantify the success of the chemistry. 


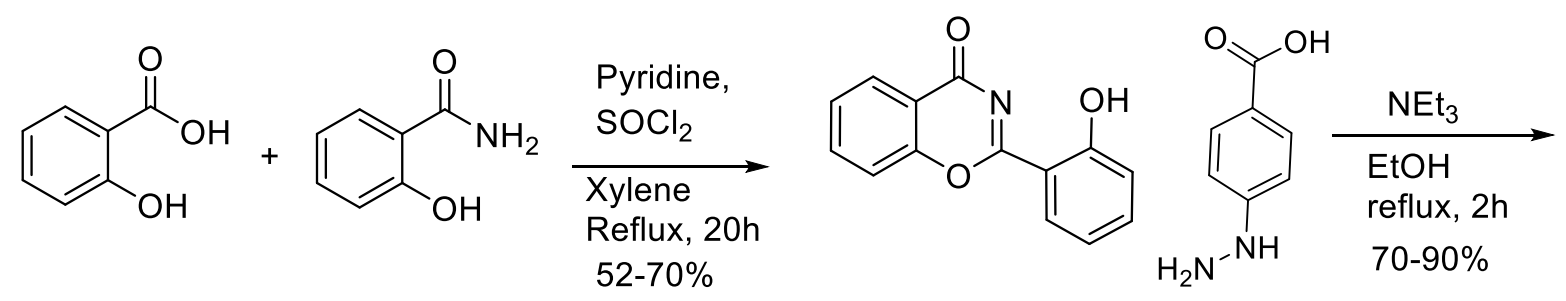<smiles>NCCNC(=O)c1ccc(-n2nc(-c3ccccc3O)nc2-c2ccccc2O)cc1</smiles>

Scheme 3. Synthesis of Deferasirox and functionalization with an amine handle.

\section{Determination of maximum phosphate binding.}

Maximum Pi binding capacity was measured by saturating the solid support, and then eluting and quantifying the bound Pi. Samples were saturated with Pi using a 1M Pi solution. Elution was carried out using $0.1 \%(\mathrm{w} / \mathrm{v})$ carboxymethyl cellulose (CMC) solution. ${ }^{37}$ The phosphate content was then quantified using a malachite green-assay. ${ }^{42}$ Pi-binding capacity is expressed as grams of Pi per kilogram of matrix (g/kg). Chitosan-flake-iron (Chito-Fe) matrix was used as the standard Pi-removal matrix against which we compared the various cellulose derivatives prepared here. We first examined the binding capacity of carboxymethyl-cellulose functionalized materials (Figure 1). In previous studies $\mathrm{CMC}$ was physiosorbed onto sawdust, followed by iron functionalization to remediate $\mathrm{Pi}^{32}$ Here, we adsorbed $\mathrm{CMC}$, covalently functionalized with one of three different $\mathrm{Fe}^{3+}$-ligands: DF, Gly or DBA, as well as unfunctionalized CMC, onto the surface of the sawdust, added the iron (III) and then measured the phosphate-binding capacity. Unmodified sawdust, 
which had still been incubated with the iron, bound very little Pi $(0.30 \pm 0.05 \mathrm{~g} / \mathrm{kg})$. The maximum binding capacity was obtained with DBA $(28.5 \pm 3.3 \mathrm{~g} / \mathrm{kg})$, with DF $(14.2 \pm 4.6 \mathrm{~g} / \mathrm{kg})$ and Gly $(14.0 \pm 2.0 \mathrm{~g} / \mathrm{kg})$ yielding binding capacities similar to that obtained by CMC alone $(11.2 \pm 1.2$ $\mathrm{g} / \mathrm{kg}$ ). However, all these $\mathrm{CMC}$ derivatives samples were more efficient phosphate binders than the chitosan-flake-iron system $(8.2 \pm 0.5 \mathrm{~g} / \mathrm{kg})$ (Figure 1).

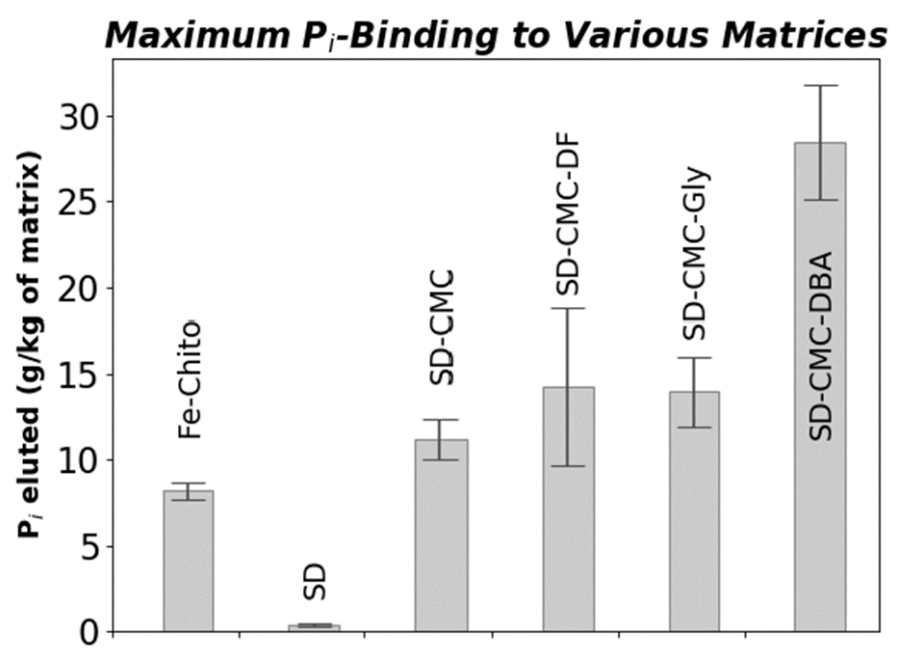

Figure 1. Quantification of the phosphate binding capacity of CMC-Sawdust Derivatives. Samples are chitosan flakes functionalized with iron (Fe-chito), untreated sawdust (SD), sawdust functionalized with only CMC (SD-CMC), sawdust conjugated to CMC functionalized with an iron chelating ligand defarsiox (SD-CMC-DF), glycine (SD-CMC-Gly) or (S)-2,4-diamino butyric acid (SD-CMC-DBA). Presented data provides the total mass of Pi (g) collected was placed over the total mass of binding matrix $(\mathrm{kg})$ to yield grams of Pi eluted per kilogram of matrix. Data represent the mean \pm standard error of the mean of an individual sample over three binding-elution cycles.

In the next stage of these studies, BA, DBA and Gly were directly functionalized onto the sawdust surface to avoid the complications inherent in $\mathrm{CMC}$-sawdust synthesis and handling. The direct 
modification of sawdust improved the Pi-binding, with SD-BA, SD-DBA and SD-Gly yielding binding capacities of $17.9 \pm 3.9 \mathrm{~g} / \mathrm{kg}, 26.7 \pm 2.5 \mathrm{~g} / \mathrm{kg}$, and $23.5 \pm 2.7 \mathrm{~g} / \mathrm{kg}$ respectively (Figure 2).

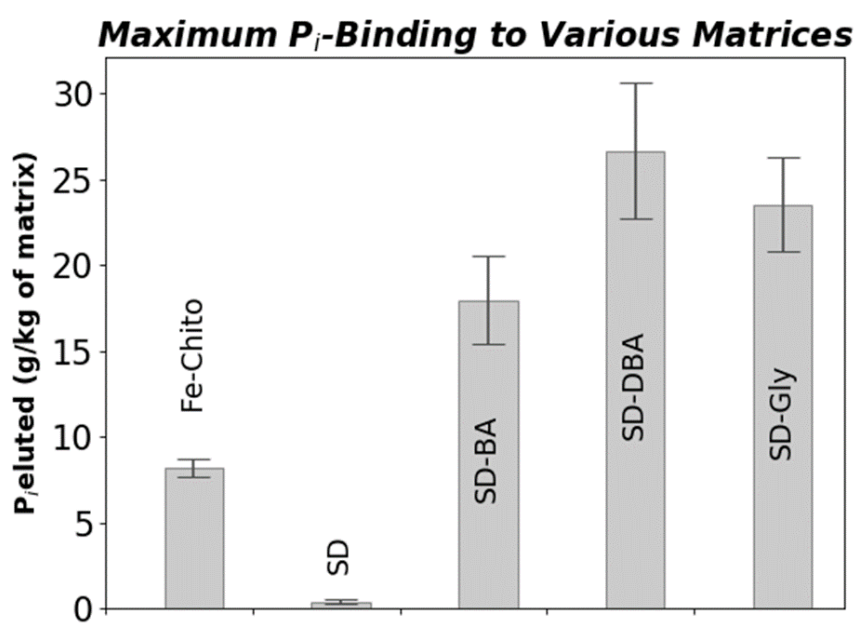

Figure 2. Maximum Binding Capacity of iron chelators directly attached to sawdust. $(n=3)$ Samples are iron chitosan flakes (Fe-Chito), sawdust without ligands (SD), sawdust functionalized with 4-amino butyric acid (SD-BA), sawdust functionalized with (S)-2,4-diamino butyric acid (SD-DBA) and sawdust functionalized with glycine (SD-Gly). Presented data provides the total mass of Pi $(\mathrm{g})$ collected was placed over the total mass of binding matrix $(\mathrm{kg})$ to yield grams of Pi eluted per kilogram of matrix. Data represent the mean \pm standard error of the mean of an individual sample over three binding-elution cycles. There is no systematic error between different binding/elution cycles.

The final ligand examined was EDA. Two different solvents were investigated for EDA functionalization of sawdust: aqueous $\mathrm{NaOH}(0.6 \mathrm{M})$ and diisopropylethylamine (DIPEA) in dioxane, with the aqueous solvent being preferable from both a green chemistry and economic perspective. The EDA ligands showed the best Pi-binding of all samples tested, with $35.1 \pm 2.1$ $\mathrm{g} / \mathrm{kg}$ and $39.9 \pm 2.7 \mathrm{~g} / \mathrm{kg}$, for dioxane and water as solvents, respectively (Figure 3). The presence 
of counter anions results in competitive binding and reduces the total Pi bound. The presence of $10 \mathrm{mM}$ sulfate, $10 \mathrm{mM}$ nitrate or $10 \mathrm{mM}$ of both sulfate and nitrate co-incubated with the SDEDA- $\mathrm{H}_{2} \mathrm{O}$ reduced bound Pi to $30.7 \pm 1.7,36.1 \pm 2.6$, and $27.4 \pm 1.5 \mathrm{~g} / \mathrm{kg}$, respectively. SD-EDAdioxane binding capacity was reduced to $25.2 \pm 2.1,26.4 \pm 2.7$ and $19.1 \pm 1.3 \mathrm{~g} / \mathrm{kg}$ in the presence of $10 \mathrm{mM}$ sulfate, nitrate, or sulfate and nitrate, respectively (Table 1).

The EDA ligands, which displayed the largest Pi-binding capacity, were further characterized for the estimation of their apparent ligand-Pi dissociation constants $\left(\mathrm{K}_{\mathrm{D}} \mathrm{App}\right)$ or $[\mathrm{Pi}]$ that results in $50 \%$ saturation of the ligand (Figure 4). The $\mathrm{K}_{\mathrm{D}}$ App values for both SD-EDA-dioxane and SD-EDA$\mathrm{H}_{2} \mathrm{O}$ treatments were calculated to be $226.8 \mathrm{mM}$.

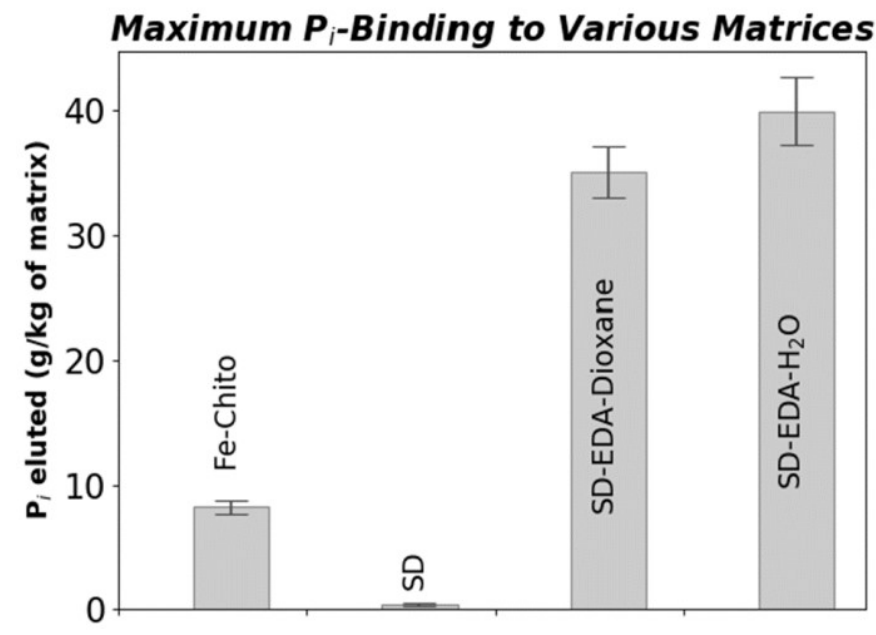

Figure 3. Maximum binding capacity of Fe-chito compared with both EDA-conjugation methods. Samples are iron functionalized chitosan flakes (Fe-Chito), sawdust without added ligands (but still incubated with the iron salt) (SD), sawdust functionalized with EDA in dioxane (SD-EDADioxane) and sawdust functionalized with EDA in water (SD-EDA- $\mathrm{H}_{2} \mathrm{O}$ ). Final functionalization occurred by bathing solid matrix samples in $50 \mathrm{mM} \mathrm{Fe} \mathrm{(III)SO}$. Presented data provides the total 
mass of Pi $(\mathrm{g})$ collected was placed over the total mass of binding matrix $(\mathrm{kg})$ to yield grams of Pi eluted per kilogram of matrix. Data represent the mean \pm standard error of the mean of an individual sample over three binding-elution cycles. There is no systematic error between different binding/elution cycles.

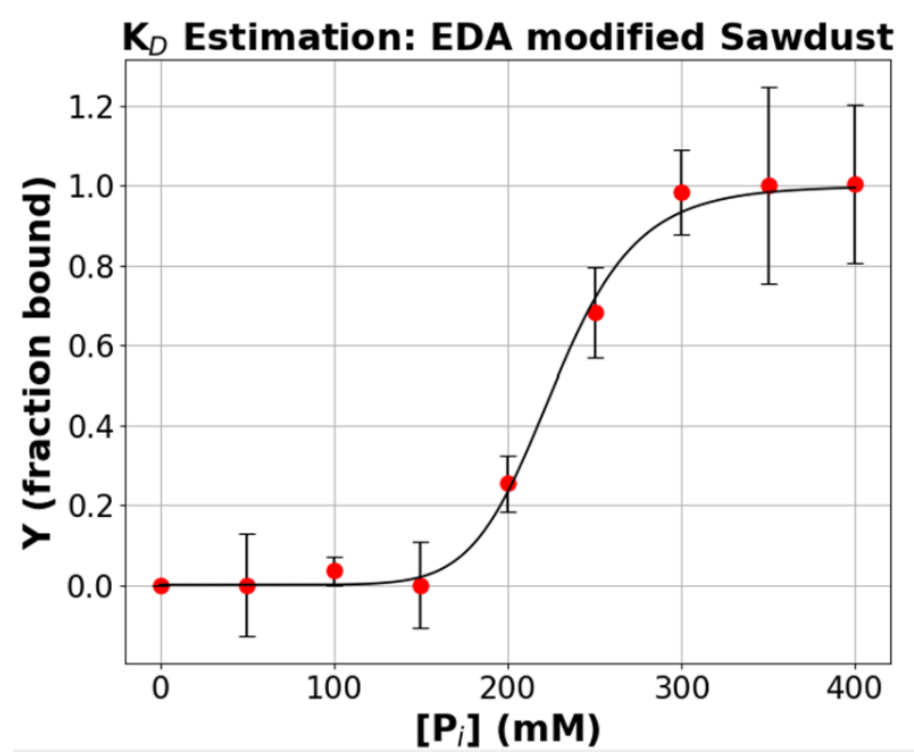

Figure 4. Saturation binding curve of sawdust functionalized with EDA in water (SD-EDA- $\mathrm{H}_{2} \mathrm{O}$ ), red dots. Phosphate was titrated into suspended resin every five minutes, aliquots were withdrawn after this five-minute incubation period for measurement using the ascorbic acid - molybdate assay. Fit curve is for SD-EDA- $\mathrm{H}_{2} \mathrm{O}$ (blue circles, blue line) using a Hill-Langmuir expression. Data is highly consistent with the Hill-Langmuir model (Eq. 1) with an $\mathrm{R}^{2}$ of 0.996.

\section{Recyclability of the resins}

Several sawdust derivatives (SD-EDA- $\mathrm{H}_{2} \mathrm{O}$, SD-GLY, SD-DBA, SD-BA) were tested for their recyclability in terms of iron retention. The sawdust was subjected to six consecutive bindingelution cycles and approximately $20 \mathrm{mg}$ of the sawdust was removed after each cycle and evaluated for iron content using ICP. A decrease is observed over the first cycles, losing approximately $70 \%$ 
of the bound iron, after which the iron content remains largely constant (Figure 5); similarly the phosphate capacity of the resin does not change systematically over the entire experiment (Figure S1) suggesting that the lost iron content was not necessarily interacting with the phosphate. SDEDA- $\mathrm{H}_{2} \mathrm{O}$ exhibited the highest iron binding over 6 washes with an average of $15.65 \mathrm{~g} \mathrm{Fe} / \mathrm{kg}$ sawdust, followed by $10.37,13.68$ and 7.55 for SD-GLY, SD-BA and SD-DBA respectively (Figure 5a). For comparison, the treated, but unfunctionalized sawdust control retained only 0.44 $\pm 0.04 \mathrm{~g} \mathrm{Fe} / \mathrm{kg}$ sawdust after the first cycle. Functionalization is required to retain iron content. However, we wanted to demonstrate the reproducibility of the synthesis, and the ability to fully regenerate the resin in the presence of fresh iron. It is possible that the reason for the reduced iron content was because the ligand was being washed out of the sawdust as it might not have been covalently immobilized. Consequently, we repeated the exercise in triplicate with SD-EDA- $\mathrm{H}_{2} \mathrm{O}$ obtained from two separate synthetic batches. After 7 wash/elution cycles, the sawdust was regenerated using the iron sulfate bath and was re-subjected to an additional 7 wash/elution cycles (Figure 5b). Power curves were fit to the data and the equations are similar, curiously, they suggest that the iron is lost more slowly in the regenerated sample though this is not a practically significant difference. This data suggests in aggregate that the resins do lose iron content over multiple uses, they are not perfectly recyclable, but they are completely regenerable.

These values could also be used to contextualize the phosphate binding results. Again, it was not possible to quantify the loading of the ligands. However, we can roughly estimate the effective ligand concentration by assuming one iron atom/ligand moiety (the other co-ordination sites would be occupied by sawdust hydroxyl groups). It is possible that in some cases two ligands bind the iron atom, but in other cases a ligand functionality might not bind an iron atom so there is some error in this estimation. From this assumption, we can calculate the maximum ligand 
loading, and the theoretical maximum phosphate binding. Comparing these values to the experimental results indicate that the sawdust resins bind between 37 and $93 \%$ of their theoretical maximum amount of phosphate/cycle (see Table 1).

Table 1. Amount of iron content (g Fe/kg sawdust) measured using ICP, average from the first three elutions to be consistent with Figures 1-3. Sawdust was taken from consecutive trials of P binding and elution.

\begin{tabular}{cccccc} 
Sample & $\begin{array}{c}\text { SD-EDA- } \\
\mathbf{H}_{2} \mathbf{O}\end{array}$ & $\begin{array}{c}\text { SD- } \\
\text { GLY }\end{array}$ & SD-BA & SD-DBA & SD \\
\hline $\begin{array}{c}\text { Average Maximum Fe content }(\mathbf{g} \\
\text { Fe/kg sawdust) }\end{array}$ & 23.81 & 13.46 & 18.80 & 11.28 & $\mathbf{0 . 4 4}$ \\
\hline $\begin{array}{c}\text { Effective ligand loading (g/kg) } \\
\text { Theoretical Maximum }\end{array}$ & 25.62 & 18.10 & 34.71 & 23.85 & \\
\hline $\begin{array}{c}\text { Phosphate Capacity (g/kg } \\
\text { sawdust) }\end{array}$ & 60.52 & 34.22 & 47.79 & 28.66 \\
\hline \hline Binding as a \% of Maximum & $66 \%$ & $69 \%$ & $37 \%$ & $93 \%$ \\
\hline \hline
\end{tabular}
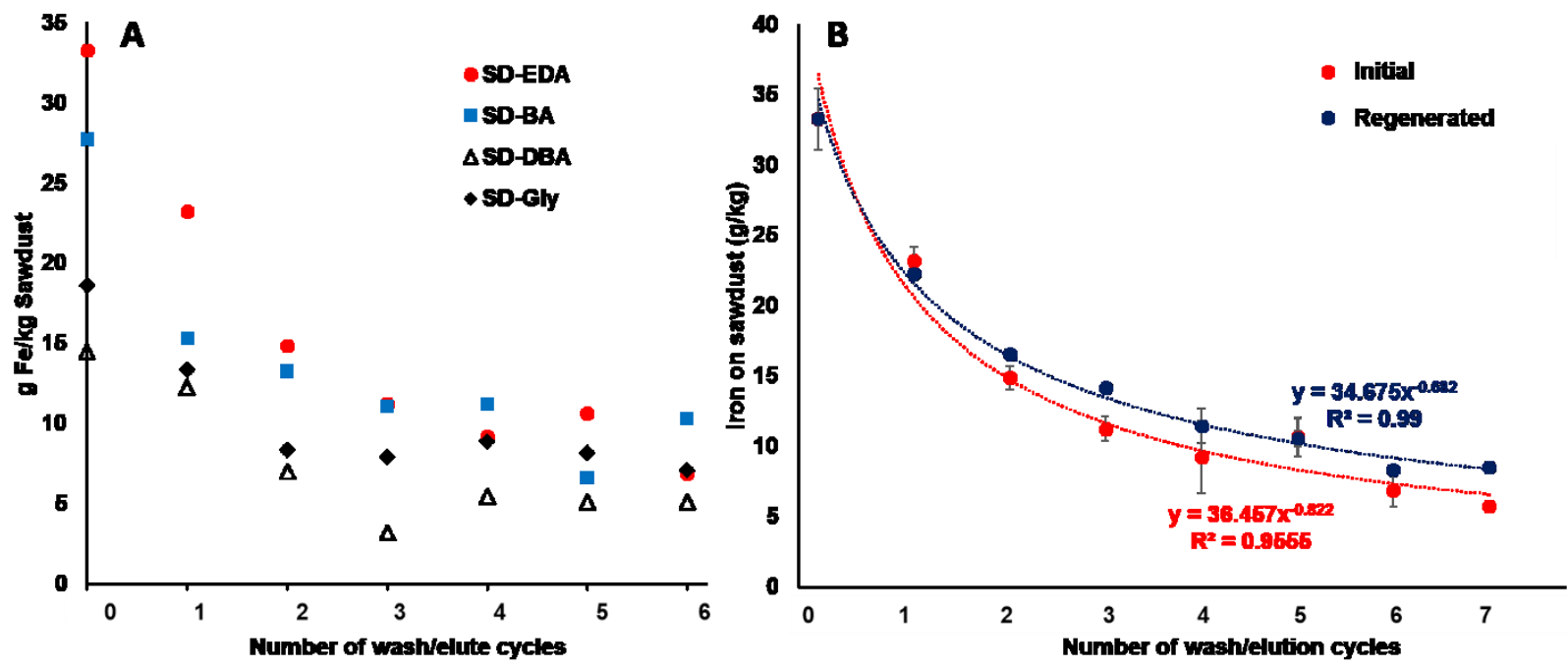

Figure 5. A) Iron content (g Fe/kg Sawdust) measured using ICP over six consecutive elution cycles of four different functionalized sawdusts. The iron chelator is attached to the sawdust via the epichlorohydin linker; B) Reproducibility of the resin behaviour, and regeneration of the resin with fresh iron. Three samples of EDA-functionalized sawdust (from two separate synthetic 
batches) were treated 7 times using our phosphate wash/elution cycles. Following the seventh elution, the sawdust was re-exposed to $\mathrm{FeCl}_{3}$ and then the wash elution cycles were repeated. The data presented is the average of the three samples with error bars representing standard error of the mean. The power law equations of the trendlines are determined where $\mathrm{x}=1+$ the number of elution cycles.

To support this contention, the eluted solvent $(200 \mathrm{~mL})$, from each of the cycles was also tested for iron content using atomic absorption spectroscopy. Little to no iron leeching was detected in SD-EDA- $\mathrm{H}_{2} \mathrm{O}, \mathrm{SD}-\mathrm{GLY}$ and SD-DBA samples. The distilled water used in the experiment contained $0.4 \mu \mathrm{g}$ of iron per $200 \mathrm{~mL}$. Very small amounts of iron were detected in the elutions from BA functionalized sawdust during cycle 3 . To contextualize these values, elutions were carried out on $5 \mathrm{~g}$ samples of the sawdust that would contain approximately $50 \mathrm{mg}$ of iron, indicating that leaching/extensive washing cycle decreased iron content by only $0.002 \%$ per cycle for $\mathrm{EDA}-\mathrm{H}_{2} \mathrm{O}$.

Table 2. The iron content $(\mu \mathrm{g} / 200 \mathrm{~mL})$ in the phosphate recovery elutions from 6 consecutive cycles of resin regeneration ( $5 \mathrm{~g}$ of resin per experiment, $200 \mathrm{ml}$ of elution solution used to regenerate the resin in each cycle) of several of the functionalized sawdust resins. Iron content tested for the presence of iron using atomic absorption spectroscopy.

$\begin{array}{rrrrr}\text { Cycle number } & \text { SD-EDA-H2O } & \text { SD-GLY } & \text { SD-BA } & \text { D SD-BA } \\ \mathbf{1} & 0.08 & 2.1 & 1.6 & 0.6 \\ \mathbf{2} & 0.7 & 1.2 & 2.4 & 0.7 \\ \mathbf{3} & 0.6 & 2.0 & 4.2 & 0.5 \\ \mathbf{4} & 0.4 & 0.7 & 0.31 & 0.4 \\ \mathbf{5} & 0.4 & 1.1 & 1.1 & 0.5 \\ \mathbf{6} & 0.5 & 0.6 & 0.9 & 0.4 \\ \mathbf{d} \mathbf{d}_{\mathbf{2}} \mathbf{O} & & 0.4 & & \end{array}$


Table 3. Pi Binding Capacity of EDA- $\mathrm{H}_{2} \mathrm{O}$ and EDA-Dioxane in the presence of sulfate and nitrate. Binding assays were conducted with $1 \mathrm{M}$ Pi containing $10 \mathrm{mM}$ sulfate, $10 \mathrm{mM}$ nitrate or $10 \mathrm{mM}$ of both sulfate and nitrate. Data represent the mean binding capacity (g Pi/kg resin) \pm the standard error of one sample over three binding-elution cycles.

\begin{tabular}{c|cccc} 
& Pi-only & Pi and sulfate & Pi and nitrate & $\begin{array}{c}\text { Pi, sulfate and } \\
\text { nitrate }\end{array}$ \\
\hline SD-EDA-H ${ }_{2} \mathrm{O}$ & $39.9 \pm 2.7$ & $30.7 \pm 1.7$ & $36.1 \pm 2.6$ & $27.4 \pm 1.5$ \\
SD-EDA- & $35.1 \pm 2.1$ & $25.2 \pm 2.1$ & $26.4 \pm 2.7$ & $19.1 \pm 1.3$ \\
Dioxane & & & & \\
& & & &
\end{tabular}

\section{Discussion}

The primary challenge in this work is attaining the required balance between the strength of iron chelation, and phosphate affinity while also ensuring that the resultant material can be made inexpensively and in a sustainable manner. Any chemically-modified material needs to be highly recyclable to make the capital cost worth the effort. Recycling requires two processes to be highly efficient: the phosphate must be relatively easy to strip from the solid support, and the iron must not be removed from the support during this process. The number of cycles over which the material remains effective is expected to be directly proportional to the affinity of the bound ligands for the iron. However, $f a c$ ligands are preferred to minimize steric hindrance-phosphate acts as a monodentate ligand ${ }^{43}$ and often forms complexes with multiple iron centres in the solid state. ${ }^{44} \mathrm{An}$ excellent ligand would likely involve significant charge-transfer to the $\mathrm{Fe}^{3+}$ centre. This would bind it tightly. Unfortunately, this would also decrease phosphate affinity. We need to identify ligands that bind the iron well, but not so well as they decrease its affinity for phosphate. 
The removal of Pi from binding resins was accomplished using ion exchange. Neutral salts and $\mathrm{pH}$ gradients have been used to remove bound $\mathrm{Pi}^{15,45}$ Low concentration acid and base solutions result in poor removal efficiency whereas high concentrations are effective but result in a degradation of the binding resin. ${ }^{46-47} \mathrm{Neutral}$ salts such as $\mathrm{NaCl}$ and $\mathrm{KCl}$ are effective and relatively inexpensive. ${ }^{15}$ However, the chloride anions are toxic to crops making the reuse of recovered Pi difficult. ${ }^{48-49}$ Alternatively, high concentrations of other anions such as sulfate, acetate and nitrate can be used but these are generally more expensive. ${ }^{50}$

The ideal recovery agent will be equally or more effective than $\mathrm{NaCl}$ but nontoxic to crops. Low concentration $\mathrm{CMC}$ can be used to the same effect. Our previous work showed that $\mathrm{CMC}$ and $\mathrm{NaCl}$ were equally effective at the removal of Pi from Fe-chito. ${ }^{37}$ However, $\mathrm{CMC}$ is nontoxic and used in a variety of industries including food and medical production. ${ }^{51}$ Abundant carboxylic acid groups mimic the phosphate starvation response in plants used to solubilize soil bound $\mathrm{Pi}^{52-53}$ Lastly, CMC is inexpensive. Therefore, for the purposes of this study, elutions were conducted using CMC.

Our first approach involved covalently immobilizing ligands to CMC (Scheme 1), and then using this to coat the sawdust particles. CMC has many carboxylate groups on its surface that we believed would assist in iron complexation and would improve phosphate-binding capacity over cellulose (the sawdust surface). CMC alone is capable of complexing with iron, and this complex then shows affinity for phosphorous as seen in our results, Figure 1, and Table 2; however, affinity is only moderate. Consequently, we sought to incorporate ligands with much higher iron binding.

Many methods have been used to modified organic biopolymers for the removal of Pi (Table 4). However, these methods can be subdivided into those relying on the impregnation of metals onto the binding resin and those relying on the introduction of higher-value amine groups to increase 
ion exchange potential with $\mathrm{Pi}^{54}$ The best results were obtained by Karachalios using an ionic liquid coating a wood surface, however this work was never published. ${ }^{55} \mathrm{We}$ sought a more tunable, and controlled approach using easily accessible materials and avoiding the use of other metals or simple physical encapsulation.

Table 4. Treatment methods and maximum binding capacities of other wood-based products for Pi adsorption.

\begin{tabular}{cccc}
\hline Resin Type & Treatment Method & $\begin{array}{c}\text { Max Pi } \\
\text { Binding }\end{array}$ & Reference \\
\hline wood particles & $\begin{array}{c}\mathrm{Fe}(\mathrm{II}) \mathrm{Cl}_{2} / \mathrm{CMC}-\text {-coating }+ \\
\mathrm{Fe}(\mathrm{II}) \mathrm{Cl}_{2}\end{array}$ & $2.05 / 17.38$ & $\begin{array}{c}\text { Eberhardt and Min } \\
(2008)\end{array}$ \\
\hline milled pine bark & $\begin{array}{c}\text { Poly-allylamine } \\
\text { hydrochloride }(\mathrm{PAA}-\mathrm{HCl})+ \\
\text { epichlorodydrin }\end{array}$ & 12.65 & Tsabalala et. al. (2004) \\
\hline $\begin{array}{c}\text { juniper bark } \\
\text { fiber }\end{array}$ & $\mathrm{La}\left(\mathrm{NO}_{3}\right)_{3} \cdot 6 \mathrm{H}_{2} \mathrm{O}(0.01 \mathrm{M})$ & 33.35 & Shin et. al. (2005) \\
\hline $\begin{array}{c}\text { milled } \\
\text { wood/bark }\end{array}$ & $\mathrm{PAA}-\mathrm{HCl}+$ epichlorodydrin \\
$\begin{array}{c}\text { yellow pine } \\
\text { wood/bark }\end{array}$ & $\begin{array}{c}\mathrm{PAA}-\mathrm{HCl} \text { or } 3 \text { chloro-2- } \\
\text { hydroxypropyl } \\
\text { trimethylammonium } \\
\text { chloride }\end{array}$ & $26.03 / 44.65$ & Karthikeyan et al. (2004) \\
\hline wood residues & $\begin{array}{c}\text { Choline chloride derivative } \\
+ \text { urea }+ \text { imidazole }\end{array}$ & $205.63 / 36.65$ & Karthikeyan et al. (2004) \\
\hline
\end{tabular}

Deferasirox is an extremely strong iron-binding ligand used in medical iron chelation therapy and was selected to maximize recyclability, although we were concerned that it might decrease phosphate affinity. The synthesis of this seemingly complex structure is very simple, and it can be rapidly accessed from very inexpensive industrial chemicals in two steps (three including addition of the ethylene diamine handle, see Scheme 3). Although the phosphate-binding capacity was moderately higher than for our previous Fe-chito substrate, the difference was disappointing considering the design considerations. We tentatively hypothesized that this limited improvement 
was due to overly strong iron chelation and low ligand loading. Evaluating functional groups commonly involved in iron chelation, and balancing this with synthetic complexity, we identified simple amines (for reactivity with the epoxide) that also contained a carboxylic acid, amine, and hydroxyl-rich groups as promising chelators. The cellulosic support provides additional hydroxyl functionalities, as does the ring-opened epichlorohydrin-derived linker (Scheme 1). This led us to select DBA, a key building block in the Trant lab, ${ }^{56} \mathrm{BA}, \mathrm{GLY}$, and EDA as ligand candidates providing an amino acid, a carboxylic acid, and an amine functionality respectively. There smaller size and better solubility would also result in higher loading on to the epichlorohydrinfunctionalized sawdust. For consistency, we also aimed to functionalize $\mathrm{CMC}$ with these substrates.

Covalent functionalization of CMC to sawdust resulted in a binding capacity of $11.2 \mathrm{~g} / \mathrm{kg}$ (Figure 1). Previous work relied on the supramolecular interaction of CMC and wood fiber to yield a product with an adsorption capacity of $17.38 \mathrm{~g} / \mathrm{kg}$ (Table 4). ${ }^{57}$ Covalently linking the CMC appears to reduce binding capacity. However, the incorporating DBA produces SD-CMC-DBA that yields a binding capacity of $28.5 \mathrm{~g} / \mathrm{kg}$ (Figure 1). Our previously studied matrix, Fe-chitosan flakes was an amine rich biopolymer that chelated cations such as iron and copper. These cations retained $\mathrm{Pi}^{30}$ The increased binding capacity of SD-CMC-DBA can be attributed to the presence of additional amine groups enhancing iron chelation and therefore Pi binding capacity.

However, functionalization of the CMC was difficult as it is only effectively soluble in water, and it forms a thick hydrogel even at low concentrations. Lyophilization was not completely effective in dehydrating the material, complicating processing. This was complicated as the free hydroxyl functionality on the $\mathrm{CMC}$ was conjugated to the epoxide functionalities on the functionalized sawdust using base and DMF as solvent. Residual water would inhibit coupling, and the poor solubility of the CMC made this an inefficient approach. Degree of functionalization on sawdust 
is likely very low as neither sawdust nor readily CMC dissolve in any of the solvents. Use of water introduces a competing nucleophile which would react more quickly with the epoxide than CMC, also resulting in a very low degree of functionalization. Due to these problems, we abandoned the approach. The added carboxylic acids of the CMC are not apparently that beneficial, and do not appear to justify the technical challenges of processing the material.

We then turned to direct functionalization of epichlorohydrin-activated sawdust, coupling DBA, BA, Gly, and EDA directly to the sawdust surface. Of these, the 1:1 combination of DBA:BA showed the best phosphate binding capacity at $26.7 \pm 2.5 \mathrm{~g} / \mathrm{kg}$ (Figure 2). This is a 3.3-fold increase over Fe-chito. SD-Deferasirox again provided a lower than expected degree of phosphate binding. This is potentially due to the extremely high affinity of deferasirox to iron; however, the most effective Pi recovery was achieved using SD-EDA, $39.9 \pm 2.7 \mathrm{~g} / \mathrm{kg}$ or $35.1 \pm 2.1 \mathrm{~g} / \mathrm{kg}$, depending on the solvent used in immobilization (Figure 3).

This is an $\sim 4.5$-fold improvement in maximum binding capacity over our previously employed Fechito binding matrix. EDA coupling to sawdust by epichlorohydrin results in the addition of amines capable of iron chelation. This is like methods that used the polymer, poly-allylamine, in place of EDA. Milled pine bark alone bound phosphate with an efficiency of $12.65 \mathrm{~g} / \mathrm{kg}$ (Table 4). ${ }^{58}$ Another study functionalized wood and wood-bark separately using poly-allylamine. They found that the functionalized bark bound $44.65 \mathrm{~g} / \mathrm{kg}$ of phosphate while the functionalized wood bound only $26.03 \mathrm{~g} / \mathrm{kg}$ (Table 4). ${ }^{59}$ Our SD-EDA is quite competitive with these methods and is far simpler to prepare (polyallylamine is an expensive polymer used primarily in biomedicine). Another method of functionalization reported in a thesis using a choline-based ionic liquid showed a binding capacity of $205.63 \mathrm{~g} / \mathrm{kg}$ (Table 4) ${ }^{55}$ In our case, the use of alternative synthetic approaches may provide higher ligand-loading, and consequently higher binding capacities. 
Another approach would be to alter the cation used from iron to lanthanum ${ }^{60}$ or zirconium ${ }^{61}$ which have been used to create highly efficient Pi retention resins. However, the inexpensive nature and biocompatibility of iron makes a lower efficiency acceptable.

The binding capacities of our systems represent idealized maximums. Application of these resins in real filters will result in exposure to other anions that will compete for available binding sites. To examine this challenge, the EDA resins were tested for Pi binding capacity in the presence of competitive anions (Table 3). SD-EDA-dioxane experiences a reduction in phosphate-binding capacity of $28.0 \%$ and $24.7 \%$ when exposed to sulfate and nitrate, respectively. SD-EDA- $\mathrm{H}_{2} \mathrm{O}$ experiences a $23.0 \%$ reduction when exposed to sulfate but only $9.5 \%$ reduction to phosphatebinding in the presence of nitrate. The presence of both sulfate and nitrate reduces the binding capacity of SD-EDA-dioxane by $45.6 \%$ the while SD-EDA- $\mathrm{H}_{2} \mathrm{O}$ only experiences a $31.3 \%$ reduction in efficiency. Therefore, given the higher Pi binding capacity, higher tolerance to nitrate interference and as water is far cheaper than dioxane and requires a simpler experimental set-up, and as dioxane is toxic and an environmental pollutant, ${ }^{62}$ the aqueous synthesis of SD-EDA shows significant promise for on site applications and is being pursued in our laboratories.

The $\mathrm{K}_{\mathrm{D} \text { App }}$ of SD-EDA- $\mathrm{H}_{2} \mathrm{O}$ was determined by fitting the fractional saturation data to the HillLangmuir equation. ${ }^{38-40}$ The Hill-Langmuir equation assumes the formation of an adsorbate monolayer on the surface of the binding resin. The $\mathrm{K}_{\mathrm{D} \text { App }}$ of SD-EDA- $\mathrm{H}_{2} \mathrm{O}$ was $226.8 \mathrm{mM}$ with a Hill coefficient of 2.46 (Figure 4). Nonlinear fitting showed a correlation coefficient, $\left(\mathrm{R}^{2}\right)$ of 0.996 suggesting the Hill-Langmuir equation adequately models the experimental results. Therefore, as Pi binds, the number of free binding sites decreases. When saturated no further binding will occur and the resin needs to be regenerated or replaced to remove further Pi from the water stream. 
The determination of $\mathrm{K}_{\mathrm{D} \text { App }}$ also allows an alternative means to measure maximum binding capacity. In general, the SD-EDA binding capacities found during batch studies agreed with those found by increasing Pi concentration. SD-EDA- $\mathrm{H}_{2} \mathrm{O}$ was found to have a maximum Pi binding capacity of $39.9 \mathrm{~g} / \mathrm{kg}$. Here the maximum was calculated to be $38.9 \mathrm{~g} / \mathrm{kg}$ with an average of 17.1 $\mathrm{mg}$ Pi bound to $0.44 \mathrm{~g}$ of resin. The SD-EDA-dioxane used in this same study massed $0.38 \mathrm{~g}$ and bound an average of $32.4 \mathrm{~g} / \mathrm{kg}$.

Hill coefficients indicate cooperativity in binding. A Hill coefficient of 5.8 indicates positive cooperativity however in this case it is likely due to a heterogeneity in available anion binding sites. This is supported by the results of the binding assays in the presence of equimolar sulfate or nitrate. Despite being present in equal amounts the reduction in P binding capacity was different.

The $\mathrm{K}_{\mathrm{D} \text { App }}$ is the concentration at which $50 \%$ of available binding sites are saturated with Pi. Previous work determined the $\mathrm{K}_{\mathrm{D} \text { App }}$ value for Fe-chito to be $138.4 \mathrm{mM}$ with a Hill coefficient of

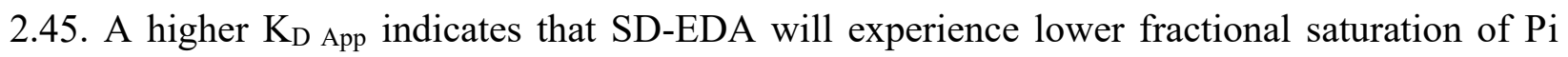
binding sites than Fe-chito at a given Pi concentration. However, the maximum binding capacity per kilogram of SD-EDA is still 4.5-fold larger. In addition, the cost of SD-EDA preparation is a fraction of the cost required to produce Fe-chito. Therefore, SD-EDA has potential for field-scale use as a Pi remediation matrix.

Strong binding and high phosphate loading are useless without reusability. The samples were examined over six consecutive cycles for Pi retention and iron loss. ICP measurements of the iron content on the sawdust show a slight decrease over the first few cycles but for the remaining cycles the amount of iron remains consistent (Figure 5). The initial iron loading for each sample can also give us some insight on minimum ligand functionalization. With no ligand, the sawdust binds 0.5 $\mathrm{g} \mathrm{Fe} / \mathrm{kg}$ of ligand. The amount of iron present on the sawdust can consequently be used to estimate 
the amount of ligand (Table 1). The highest loading observed is $34.7 \mathrm{~g} / \mathrm{kg}$ of SD-BA, with SDGly only loading at $18.1 \mathrm{~g} / \mathrm{kg}$. This also allows for a calculation of the maximum phosphate capacity of each formulation. The SD-EDA has the highest possible capacity at $60.5 \mathrm{~g} / \mathrm{kg}$ while SD-DBA has the lowest at $28.7 \mathrm{~g} / \mathrm{kg}$. Curiously, when we compare these values with the experimental phosphate binding results (Figures 2 and 3), we can observe that the SD-DBA binds near its maximum capacity, while SD-EDA is working at only $66 \%$ efficiency potentially because it is a poorer ligand for iron. This suggests that improving the reaction conditions to load DBA would likely significantly improve efficacy of the resin, but this would come at a significantly greater cost. ${ }^{63}$ In general, the phosphate binding assays agree well with the ICP measured values for iron content further supporting the supposition that these materials retain their iron and can effectively collect phosphate. Even after several cycles of use, the phosphate binding capacity of the SD-EDA stabilizes around $10 \mathrm{~g}$ of phosphate/kg of sawdust (Figure S1) which is comparable to other resins (Table 4).

Additionally, measuring the iron concentration of the elutions show little to no iron leeching from the sawdust during elution. This is promising regarding the recyclability of the material: these ligands provide acceptable retention of the iron. However, iron content does fall over multiple cycles as it co-elutes with the phosphate. To address this limitation, we wanted to ensure that we could regenerate the resin and that the decrease in the iron content was not due to damage to the resin itself involving loss of the ligands. To explore this question we resynthesized SD-EDA and compared the iron content in the different batches over 14 cycles with the iron content regenerated after cycle 7 (Figure 5b). This study demonstrates that there is very little variance in the iron content, and by extension the ligand content, in the different batches of the SD-EDA, and that when resin that has undergone 7 cycles of collecting and eluting phosphate is regenerated in an 
iron sulfate bath, it completely recovers its iron binding potential. The curves of the original and regenerated resins are quite similar, except that a small, but systematically more iron was present in the regenerated sawdust than in the original batch. Regardless, it is clear that the ligand is not being lost (without the ligand, only $0.44 \pm 0.04 \mathrm{~g}$ Fe $/ \mathrm{kg}$ binds) during the process. Together these data suggest that the synthesis is highly robust and reproducible and is strong evidence that the ligands are not removed from the resin during mixing with solutions or elution of the phosphate. However, the lifespan of the SD-EDA- $\mathrm{H}_{2} \mathrm{O}$ biopolymer in wastewater needs to be determined: 14 cycles is not enough to explore this question: Fe-chito suffers from breakdown over a couple of months. If SD-EDA- $\mathrm{H}_{2} \mathrm{O}$ survives better in the field than this will further increase the cost efficiency of this material. A limitation of using sawdust for this derivation process is the breakdown of some sawdust into microparticles during agitation of the reaction mixtures, making the implementation of these materials for large scale filtration difficult. Alternative synthetic methods that are gentler on the sawdust but yielding the same results need to be explored.

Cellulosic and other polysaccharidic materials have long been promising candidates for the remediation of undesirable elements from wastewater, as they are inexpensive waste products themselves, and are readily available from the agricultural and forestry industries ${ }^{64-66}$ Recycling adds value to these waste products, but for phosphate-binding it is clear that the cellulose needs to be modified. As iron-phosphate complexes are particularly stable, the modification of the surface of solid cellulosic materials with iron-binding ligands appears to be a particularly promising approach, and further studies examining its deployment in the field are currently under way.

\section{Conclusion:}

Several ligands were immobilized on sawdust, either directly using epichlorohydrin linkers, or indirectly using carboxymethylcellulose. The latter materials were challenging to work with and 
the limited processability restricts their future commercial application. High iron binding is required to maintain recyclability of the resin, but overly strong iron binding can potentially limit phosphate affinity. Although all tested systems outperformed our previous best candidate, Fechitosan $(8.2 \pm 1.5 \mathrm{~g} / \mathrm{kg})$, the exceptionally potent iron-binding ligand Deferasirox proved to be a largely ineffective system for phosphate remediation $(14.2 \pm 12.1 \mathrm{~g} / \mathrm{kg})$. Ethylene diamine $/ \mathrm{Fe}$ (III)functionalized sawdust, synthesized in three steps under entirely aqueous conditions, proved to be a highly effective and recyclable phosphate-binding ligand $(39.9 \pm 8.1 \mathrm{~g} / \mathrm{kg}), 4.5$-fold more active than the far more expensive chitosan-Fe. These sawdust-functionalized materials show good promise as next generation recyclable phosphate-recovering ligands and further field tests are underway in our laboratory.

\section{Acknowledgements:}

This work was supported by an Ontario Graduate Scholarship to D.M. and the Natural Sciences and Engineering Research Council of Canada (NSERC, JFT grant no. 2018-06338 and BM grant no 2017-04925). The authors declare no competing financial interest.

Supporting Information: Full experimental details for each sawdust-ligand system, details regarding EDA loading, ${ }^{1} \mathrm{H}$ NMR of all synthesized DF precursors, including the first assigned spectrum of DF, and FT-IR spectra of all sawdust constructs.

\section{References}

1. Cordell, D.; Drangert, J.-O.; White, S., The story of phosphorus: Global food security and food for thought. Glob. Environ. Change 2009, 19 (2), 292-305. DOI:

10.1016/j.gloenvcha.2008.10.009

2. Walker, T.; Syers, J., The fate of phosphorous during pedogenesis. Geoderma 1976, 15, 1-19. DOI: 10.1016/0016-7061(76)90066-5

3. Schindler, D., Evolution of phosphorous limitation in lakes. Science 1977, 195 (4275), 260-262. DOI: 10.1126/science.195.4275.260 
4. Downing, J.; McCauley, E., The nitrogen: phosphorous relationship in lakes. Limnol. Oceangeo. 1992, 37 (5), 936 - 945. DOI: 10.4319/1o.1992.37.5.0936

5. Anderson, D.; Gilbert, P.; Burkholder, J., Harmful algal blooms and eutrophication: nutrient sources, composition and consequences. Estuaries Coasts 2002, 25 (5), 704-725. DOI: 10.1007/BF02804901

6. Desmidt, E.; Ghyselbrecht, K.; Zhang, Y.; Pinoy, L.; Van der Bruggen, B.; Verstraete, W.; Rabaey, K.; Meesschaert, B., Global Phosphorus Scarcity and Full-Scale P-Recovery Techniques: A Review. Crit. Rev. Environ. Sci. Technol. 2015, 45 (4), 336-384. DOI: 10.1080/10643389.2013.866531

7. Durrant, A. E.; Scrimshaw, M. D.; Stratful, I.; Lester, J. N., Review of the Feasibility of Recovering Phosphate from Wastewater for Use as a Raw Material by the Phosphate Industry. Environ. Technol. 1999, 20 (7), 749-758. DOI: 10.1080/09593332008616870

8. Berg, U.; Knoll, G.; Kaschka, E.; Weidler, P. G.; Nüesch, R., Is Phosphorus Recovery from Waste Water Feasible? Environ. Technol. 2007, 28 (2), 165-172. DOI: 10.1080/09593332808618774

9. Doyle, J. D.; Parsons, S. A., Struvite formation, control and recovery. Water Res. 2002, 36 (16), 3925-3940. DOI: 10.1016/S0043-1354(02)00126-4

10. Peng, L.; Dai, H.; Wu, Y.; Peng, Y.; Lu, X., A comprehensive review of phosphorus recovery from wastewater by crystallization processes. Chemosphere 2018, 197, 768-781. DOI: 10.1016/j.chemosphere.2018.01.098

11. Caravelli, A. H.; Contreras, E. M.; Zaritzky, N. E., Phosphorous removal in batch systems using ferric chloride in the presence of activated sludges. J. Hazard. Mater. 2010, 177 (1-3), 199-208. DOI: 10.1016/j.jhazmat.2009.12.018

12. Wang, X.; Lü, S.; Gao, C.; Feng, C.; Xu, X.; Bai, X.; Gao, N.; Yang, J.; Liu, M.; Wu, L., Recovery of Ammonium and Phosphate from Wastewater by Wheat Straw-based Amphoteric Adsorbent and Reusing as a Multifunctional Slow-Release Compound Fertilizer. ACS Sustainable Chem. Eng. 2016, 4 (4), 2068-2079. DOI: 10.1021/acssuschemeng.5b01494 13. Zhang, J.; Shen, Z.; Mei, Z.; Li, S.; Wang, W., Removal of phosphate by Fe-coordinated amino-functionalized 3d mesoporous silicates hybrid materials. J. Environ. Sci. (Beijing, China) 2011, 23 (2), 199-205. DOI: 10.1016/s1001-0742(10)60393-2

14. Zhu, Z.; Zeng, H.; Zhu, Y.; Yang, F.; Zhu, H.; Qin, H.; Wei, W., Kinetics and thermodynamic study of phosphate adsorption on the porous biomorph-genetic composite of $\alpha$ Fe2O3/Fe3O4/C with eucalyptus wood microstructure. Sep. Purif. Technol. 2013, 117, 124-130. DOI: 10.1016/j.seppur.2013.05.048

15. Loganathan, P.; Vigneswaran, S.; Kandasamy, J.; Bolan, N. S., Removal and Recovery of Phosphate From Water Using Sorption. Crit. Rev. Environ. Sci. Technol. 2014, 44 (8), 847-907. DOI: 10.1080/10643389.2012.741311

16. Martin, B. D.; Parsons, S. A.; Jefferson, B., Removal and recovery of phosphate from municipal wastewaters using a polymeric anion exchanger bound with hydrated ferric oxide nanoparticles. Water Sci. Technol. 2009, 60 (10), 2637-2645. DOI: 10.2166/wst.2009.686 17. Nur, T.; Johir, M. A. H.; Loganathan, P.; Nguyen, T.; Vigneswaran, S.; Kandasamy, J., Phosphate removal from water using an iron oxide impregnated strong base anion exchange resin. J. Ind. Eng. Chem. (Amsterdam, Neth.) 2014, 20 (4), 1301-1307. DOI: 10.1016/j.jiec.2013.07.009 
18. Beyeh, N. K.; Diez, I.; Taimoory, S. M.; Meister, D.; Trant, J. F.; Ras, R. H. A.;

Rissanen, K., High-affinity and selective detection of pyrophosphate in water by a resorcinarene salt receptor. Chem. Sci. 2018, 9, 1358-1367. DOI: 10.1039/C7SC05167K

19. Cao, D.; Jin, X.; Gan, L.; Wang, T.; Chen, Z., Removal of phosphate using iron oxide nanoparticles synthesized by eucalyptus leaf extract in the presence of CTAB surfactant.

Chemosphere 2016, 159, 23-31. DOI: 10.1016/j.chemosphere.2016.05.080

20. Kartashevsky, M.; Semiat, R.; Dosoretz, C. G., Phosphate adsorption on granular ferric hydroxide to increase product water recovery in reverse osmosis-desalination of secondary effluents. Desalination 2015, 364, 53-61. DOI: 10.1016/j.desal.2015.02.038

21. Namasivayam, C.; Sangeetha, D., Removal and recovery of nitrate from water by $\mathrm{ZnCl}_{2}$ activated carbon from coconut coir pith, an agricultural solid waste. Indian J. Chem. Technol.

2005, 12 (5), 513-521. DOI:

22. Su, C., Environmental implications and applications of engineered nanoscale magnetite and its hybrid nanocomposites: A review of recent literature. J. Hazard. Mater. 2016, 322 (Part A), 48-84. DOI: 10.1016/j.jhazmat.2016.06.060

23. Zach-Maor, A.; Semiat, R.; Shemer, H., Synthesis, performance, and modeling of immobilized nano-sized magnetite layer for phosphate removal. J. Colloid Interface Sci. 2011, 357 (2), 440-446. DOI: 10.1016/j.jcis.2011.01.021

24. Drenkova-Tuhtan, A.; Schneider, M.; Franzreb, M.; Meyer, C.; Gellermann, C.; Sextl, G.; Mandel, K.; Steinmetz, H., Pilot-scale removal and recovery of dissolved phosphate from secondary wastewater effluents with reusable $\mathrm{ZnFeZr}$ adsorbent $@ \mathrm{Fe}_{3} \mathrm{O}_{4} / \mathrm{SiO}_{2}$ particles with magnetic harvesting. Water Res. 2017, 109, 77-87. DOI: 10.1016/j.watres.2016.11.039

25. Kim, M.; Park, K.; Kim, J. M., Phosphate recovery from livestock wastewater using iron oxide nanotubes. Chem. Eng. Res. Des. 2016, 114, 119-128. DOI: 10.1016/j.cherd.2016.06.016 26. Bunce, J. T.; Ndam, E.; Ofiteru, I. D.; Moore, A.; Graham, D. W., A review of phosphorus removal technologies and their applicability to small-scale domestic wastewater treatment systems. Front. Environ. Sci. 2018, 6. DOI: 10.3389/fenvs.2018.00008

27. Anirudhan, T. S.; Rauf, T. A.; Rejeena, S. R., Removal and recovery of phosphate ions from aqueous solutions by amine functionalized epichlorohydrin-grafted cellulose. Desalination 2012, 285, 277-284. DOI: 10.1016/j.desal.2011.10.014

28. Anirudhan, T. S.; Senan, P., Adsorption of phosphate ions from water using a novel cellulose-based adsorbent. Chem. Ecol. 2011, 27 (2), 147-164. DOI:

10.1080/02757540.2010.547487

29. Unnithan, M. R.; Vinod, V. P.; Anirudhan, T. S., Ability of iron(III)-loaded carboxylated polyacrylamide-grafted sawdust to remove phosphate ions from aqueous solution and fertilizer industry wastewater: Adsorption kinetics and isotherm studies. J. Appl. Polym. Sci. 2002, 84 (13), 2541-2553. DOI: 10.1002/app.10579

30. Yep, T. Application of chitosan in the treatment of wastewater from agricultural sources. University of Windsor, Windsor, 2016. URL:

31. Ahmad, M.; Ahmed, S.; Swami, B. L.; Ikram, S., Adsorption of heavy metal ions: Role of chitosan and cellulose for water treatment. Int. J. Pharm. Sci. Res. 2015, 2 (6), 280-289. DOI: 10.13040/ijpsr.0975-8232.ijp.2(6).280-89

32. Eberhardt, T. L.; Min, S.-H.; Han, J. In Characterization and treatment of wood fibre for phosphate removal from water, 9th International Conference on Environmental Science and Technology, Rhodes, Greece, Global Network for Environmental Science and Technology: Rhodes, Greece, 2005; pp 355-361. 
33. Halawi, R.; Motta, I.; Taher, A.; Cappellini, M. D., Deferasirox: an orphan drug for chronic iron overload in non-transfusion dependent thalassemia syndromes. Expert Opin. Orphan Drugs 2016, 4 (6), 677-686. DOI: 10.1080/21678707.2016.1182018

34. Taher, A.; Cappellini, M. D., Update on the use of deferasirox in the management of iron overload. Ther. Clin. Risk Manage. 2009, 5, 857-868. DOI: 10.2147/TCRM.S5497

35. Steinhauser, S.; Heinz, U.; Bartholomä, M.; Weyhermüller, T.; Nick, H.; Hegetschweiler, K., Complex Formation of ICL670 and Related Ligands with Fe(III) and Fe(II). Eur. J. Inorg. Chem. 2004, 2004 (21), 4177-4192. DOI: 10.1002/ejic.200400363

36. Arduini, M.; Felluga, F.; Mancin, F.; Rossi, P.; Tecilla, P.; Tonellato, U.; Valentinuzzi, N., Aluminium fluorescence detection with a FRET amplified chemosensor. Chem. Commun. (Cambridge, U. K.) 2003, (13), 1606-1607. DOI: 10.1039/b303195k

37. Ure, D.; Awada, A.; Frowley, N.; Munk, N.; Stanger, A.; Mutus, B., Greenhouse tomato plant roots/carboxymethyl cellulose method for the efficient removal and recovery of inorganic phosphate from agricultural wastewater J Environ. Manage. 2019, 233, 258-263. DOI:

10.1016/j.jenvman.2018.12.053

38. Pollard, T. D., A guide to simple and informative binding assays. Mol. Biol. Cell 2010, 21 (23), 4061-4067. DOI: 10.1091/mbc.E10-08-0683

39. Prinz, H., Hill coefficients, dose-response curves and allosteric mechanisms. J. Chem. Biol. 2010, 3 (1), 37-44. DOI: 10.1007/s12154-009-0029-3

40. Gesztelyi, R.; Zsuga, J.; Kemeny-Beke, A.; Varga, B.; Tosaki, A., The Hill equation and the origin of quantitative pharmacology Arch. Hist. Exact Sci. 2012, 66, 427-438. DOI: 10.1007/s00407-012-0098-5

41. Williams, A.; Ibrahim, I. T., A new mechanism involving cyclic tautomers for the reaction with nucleophiles of the water-soluble peptide coupling reagent 1-ethyl-3-(3'(dimethylamino)propyl)carbodiimide (EDC). J. Am. Chem. Soc. 1981, 103 (24), 7090-7095. DOI: $10.1021 /$ ja00414a011

42. Feng, J.; Chen, Y.; Pu, J.; Yang, X.; Zhang, C.; Zhu, S.; Zhao, Y.; Yuan, Y.; Yuan, H.; Liao, F., An improved malachite green assay of phosphate: Mechanism and application. Anal. Biochem. 2011, 409 (1), 144-149. DOI: 10.1016/j.ab.2010.10.025

43. Al-Sogair, F.; Marafie, H. M.; Shuaib, N. M.; Youngo, H. B.; El-Ezaby, M. S., Interaction of Phosphate with Iron(III) in Acidic Medium, Equilibrium and Kinetic Studies. $J$. Coord. Chem. 2002, 55 (9), 1097-1109. DOI: 10.1080/0095897021000010053

44. Song, Y.; Zavalij, P. Y.; Suzuki, M.; Whittingham, M. S., New Iron(III) Phosphate Phases: Crystal Structure and Electrochemical and Magnetic Properties. Inorg. Chem. 2002, 41 (22), 5778-5786. DOI: 10.1021/ic025688q

45. Ngo, H. H.; Guo, W.; Hang Nguyen, T. A.; Surampalli, R. Y.; Zhang, T. C., Agricultural By-Products for Phosphorous Removal and Recovery from Water and Wastewater: A Green Technology. In Green Technologies for Sustainable Water Management, Ngo, H. H.; Guo, W.; Surampalli, R. Y.; Zhang, T. C., Eds. American Society of Civil Engineers: Reston, VA, 2016; pp 491-531. DOI: 10.1061/9780784414422.ch14

46. De Lima, A. C. A.; Nascimento, N. A.; De Sousa, F. F.; Filho, J. M.; Oliveira, A. C., Modified coconut shell fibers: A green and economical sorbent for the removal of anions from aqeuous solution. Chem. Eng. J. (Amsterdam, Neth.) 2012, 185-186, 274-284. DOI: 10.1016/j.cej.2012.01.037 
47. Anirudhan, T.; Noeline, B.; Manohar, D., Phosphate removal from wastewaters using a weak anion exchanger prepared from a lignocellulosic material. Environ. Sci. Technol. 2006, 40, 2740-2745. DOI: 10.1021/es052070h

48. Lee, M. K.; Van Iersel, M. W., Sodium chloride effects on growth, morphology and physiology of chrysanthemum (chrysanthemum morifolium). HortScience 2008, 43 (6), 18881891. DOI:

49. Tavakkoli, E.; Rengasamy, P.; McDonald, G. K., High concentrations of Na+ and Clions in soil solution have simultaneous detrimental effects on growth of faba bean under salinity stress. J. Exp. Bot. 2010, 61 (15), 4449-59. DOI: 10.1093/jxb/erq251

50. Mehta, C. M.; Khunjar, W. O.; Nguyen, V.; Tait, S.; Batstone, D. J., Technologies to Recover Nutrients from Waste Streams: A Critical Review. Crit. Rev. Environ. Sci. Technol. 2014, 45 (4), 385-427. DOI: 10.1080/10643389.2013.866621

51. Ginkel, C. G. V.; Gayton, S., The biodegradability and non-toxicity of CMC (0.7 DS) and intermediates. Environ. Toxicol. Chem. 1996, 15 (3), 270-274. DOI: 10.1002/etc.5620150307

52. Neumann, G.; Römheld, V., Root excretion of carboxylic acids and protons in phosphorous-deficient plants. Plant Soil 1999, 211, 121-130. DOI: 10.1023/A:1004380832118

53. Secco, D.; Jabnoune, M.; Walker, H.; Shou, H.; Wu, P.; Poirier, Y.; Whelan, J., Spatiotemporal transcript profiling of rice roots and shoots in response to phosphate starvation and recovery. Plant Cell 2013, 25 (11), 4285-4304. DOI: 10.1105/tpc.113.117325

54. Wang, W. Y.; Yue, Q. Y.; Xu, X.; Gao, B. Y.; Zhang, J.; Li, Q.; Xu, J. T., Optimized conditions in preparation of giant reed quaternary amino anion exchanger for phosphate removal Chem. Eng. J. (Amsterdam, Neth.) 2010, 157, 161-167. DOI: 10.1016/j.cej.2009.11.024

55. Karachalios, A. P. Nutrient removal from water by various quaternized wood agricultural residues using a choline based ionic liquid analogue. Stevens Institute of Technology, Hoboken, New Jersey, 2012. URL:

56. Ferraiuolo, R.-M.; Meister, D.; Leckie, D.; Dashti, M.; Franke, J.; Porter, L. A.; Trant, J. F., Neuro and heparic toxicological profile of $(S)$-2,4-diaminobutyric acid in embryonic, adolescent and adult zebrafish. J. Appl. Toxicol. 2019, 39, 1568-1577. DOI: 10.1002/jat.3840

57. Eberhardt, T. L.; Min, S. H., Biosorbents prepared from wood particles treated with anionic polymer and iron salt: effect of particle size on phosphate adsorption. Bioresour.

Technol. 2008, 99 (3), 626-30. DOI: 10.1016/j.biortech.2006.12.037

58. Tshabalala, M.; G. Karthikeyan, K.; Wang, D., Cationized milled pine bark as an adsorbent for orthophosphate anions. J. Appl. Polym. Sci. 2004, 93, 1577-1583. DOI:

10.1002/app.20637

59. Karthikeyan, K. G.; Tshabalala, M. A.; Wang, D.; Kalbasi, M., Solution chemistry effects on orthophosphate adsorption by cationized solid wood residues. Environ. Sci. Technol. 2004, 38, 904-911. DOI: 10.1021/es034819z

60. Shin, E. W.; Karthikeyan, K. G.; Tshabalala, M. A., Orthophosphate sorption onto lanthanum-treated lignocellulosic sorbents. Environ. Sci. Technol. 2006, 33, 6273-6279. DOI: 10.1021/es048018n

61. Ohura, S.; Harada, H.; Biswas, B. K.; Kondo, M.; Ishikawa, S.; Kawakita, H.; Ohto, K.; Inoue, K., Phosphorous recovery from secondary effluent and side-stream liquid in a sewage plant using zirconium-loaded saponified orange waste. J. Mater. Cycle Waste Manage. 2011, 31, 293-297. DOI: 10.1007/s10163-011-0029-6 
62. Stepien, D. K.; Diehl, P.; Helm, J.; Thoms, A.; Püttmann, W., Fate of 1,4-dioxane in the aquatic environment: From sewage to drinking water. Water Res. 2014, 48, 406-419. DOI: 10.1016/j.watres.2013.09.057

63. As of October 10, the list price of DL-DBA on Sigma Aldrich is $\$ 2,170.00 \mathrm{CAD}$ for $25 \mathrm{~g}$ as opposed to $\$ 83.00 \mathrm{CAD}$ for $2.5 \mathrm{~L}$ of EDA.

64. Olivera, S.; Muralidhara, H. B.; Venkatesh, K.; Guna, V. K.; Gopalakrishna, K.; Kumar K, Y., Potential applications of cellulose and chitosan nanoparticles/composites in wastewater treatment: A review. Carbohydr. Polym. 2016, 153, 600-618. DOI:

10.1016/j.carbpol.2016.08.017

65. Abouzeid, R. E.; Khiari, R.; El-Wakil, N.; Dufresne, A., Current State and New Trends in the Use of Cellulose Nanomaterials for Wastewater Treatment. Biomacromolecules 2018. DOI: 10.1021/acs.biomac.8b00839

66. Vandenbossche, M.; Jimenez, M.; Casetta, M.; Traisnel, M., Remediation of Heavy Metals by Biomolecules: A Review. Crit. Rev. Environ. Sci. Technol. 2015, 45 (15), 1644-1704. DOI: $10.1080 / 10643389.2014 .966425$ 


\section{For Table of contents use only:}

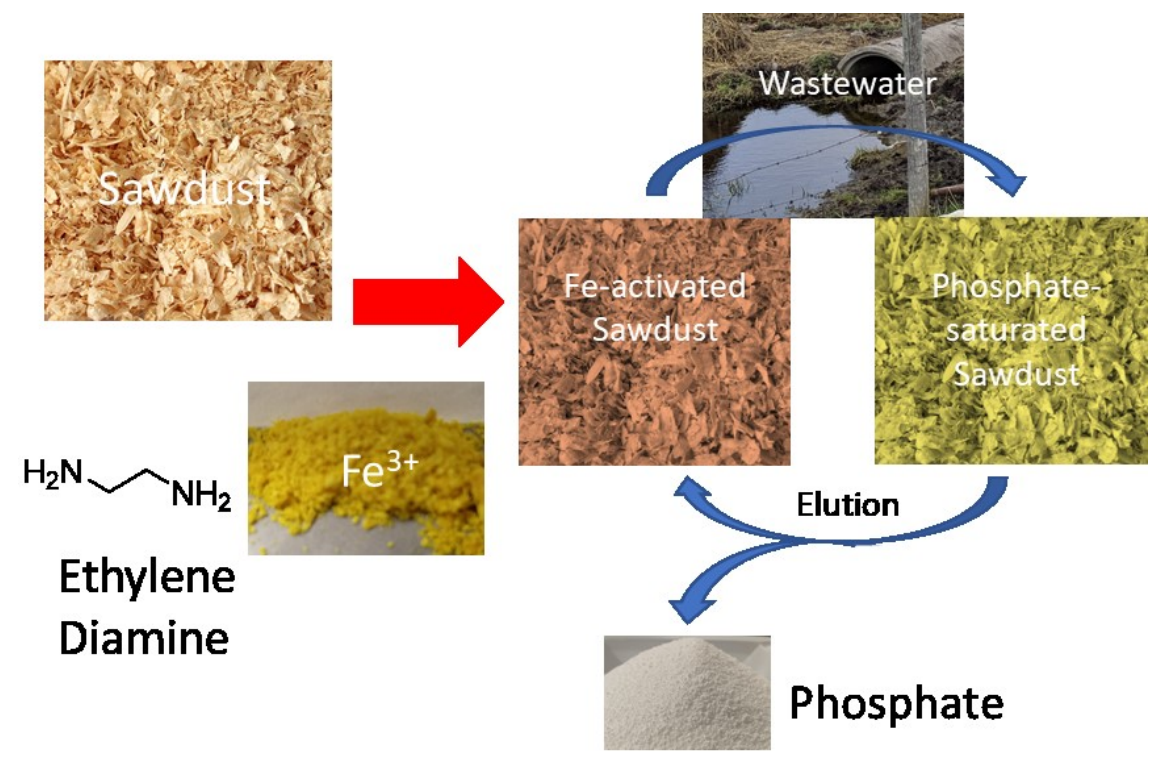

Synopsis: Recyclable, inexpensive resins for phosphate recovery from wastewater are essential. A sawdust-based system is reported with excellent phosphate binding capacity. 